\title{
Estudio comparativo del diferencial de precios agrarios entre productores y consumidores por países en el ámbito mundial bajo criterios de seguridad alimentaria de abastecimiento
}

\author{
José Ruiz Chico a , ANTONio Rafael PeÑa SÁNCHEZ ${ }^{\text {a }}$, MERCEDEs JimÉNEZ \\ GARCíA ${ }^{\text {a }}$ \\ a Universidad de Cádiz, Facultad de Ciencias Sociales y de la Comunicación, Avda. de la \\ Unviersidad, s/n, 11405 Jerez de la Frontera (Cádiz), España. E-mail: jose.ruizchico@uca.es, \\ rafael.pena@uca.es, mercedes.jimenezgarcia@uca.es
}

\begin{abstract}
RESUMEN
En los últimos años, la seguridad alimentaria de abastecimiento es una de las cuestiones más importantes en la ciencia económica. En este trabajo, este concepto se vinculará con el precio de los alimentos, exactamente con el diferencial de precios entre productores y consumidores. El objetivo de este artículo es el estudio de estas variables en 73 países de todo el mundo, para identificar perfiles de comportamiento comunes. Para ello, se utilizarán las metodologías cluster y CHAID para analizar este tema. Se puede concluir que en los países desarrollados los márgenes alimentarios han aumentado mientras que los indicadores de seguridad alimentaria han permanecido estables, mientras que en los países en vías de desarrollo los márgenes disminuyen ante mejoras notables de esos indicadores.
\end{abstract}

Palabras clave: Desarrollo humano, economía regional, alimentación, hambre.

\section{Comparative Study of Differential Agricultural Prices between Producers and Consumers per Country Worldwide under Supply Food Safety Criteria}

\begin{abstract}
In recent years, food supply security is one of the most important issues in economic science. In this paper, this concept will be linked to the price of food, exactly with the price differential between producers and consumers. The aim of this article is to study these variables in 73 countries worldwide to identify common profiles of behaviour. With such aim in mind, the cluster and CHAID methodologies will be used to analyse this topic. It can be concluded that in developed countries food margins have increased while food security indicators have remained stable, while in developing countries margins have declined in the face of marked improvements in these indicators.
\end{abstract}

Keywords: Human Development, Regional Economy, Food, Hunger.

Clasificación JEL: O13, R50, Q19

Artículo recibido en mayo de 2016 y aceptado en febrero de 2017

Artículo disponible en versión electrónica en la página www.revista-eea.net, ref. ə-35206

ISSN 1697-5731 (online) - ISSN 1133-3197 (print) 


\section{INTRODUCCIÓN}

El objetivo de este artículo es el estudio de la evolución del diferencial de precios alimentarios entre consumidores y productores a nivel mundial, desde la perspectiva de la seguridad alimentaria de abastecimiento como indicador del nivel de pobreza, para detectar perfiles de comportamiento comunes en los países que componen la muestra. Ambos conceptos, precio de los alimentos y seguridad alimentaria de abastecimiento, están muy relacionados entre sí, ya que una disminución en los mismos supondría una clara ayuda en la lucha contra la desnutrición en concreto y la pobreza en general.

Como variable principal de este trabajo, el precio de los alimentos ha sido un tema muy estudiado en la literatura económica, pudiendo citar como ejemplos desde una perspectiva general los trabajos de Gracia y Albisu (1996), Pérez y Matea (2005), Atance y García (2008), Martínez y García (2010), Durán (2011), Cascante (2012) y Handbury y Weinstein (2015). El problema de los altos precios es tratado por autores como Headey y Fan (2008), Gilbert (2010), Arslan (2011), Soto y Rapallo (2012), Jódar (2011) y Bellemare (2015). Así, Amarillo (2004) reflexiona sobre ellos en el contexto de la desigualdad económica. Casadevall (2011) estudia esta cuestión en una perspectiva internacional, mientras que Cavero (2008) se centra el caso de los países en desarrollo.

En este trabajo se da un paso más allá porque, más que los precios alimentarios en sí, se analiza el diferencial de precios alimentarios entre consumidores y productores, una cuestión muy debatida en los últimos años desde el punto de vista económico e incluso ético. Herrero (2007) describe problema argumentando que genera quejas en los productores ante la sociedad y la Administración Pública, interés en los consumidores e inquietud en los distribuidores. De esta manera, más concretamente, Brambila et al. (2013) intentan determinar el precio mínimo que debe pagarse al productor lácteo en México, para reducir la posible dependencia de estas importaciones sin aumentar el precio al consumidor. Larrubia (1996) estudia este problema desde un punto de vista histórico. Por sectores, Sierra et al. (2005) analizan los márgenes entre productor y consumidor en el sector porcino en México. Eslava et al. (2007) estudian el caso de la carne de vacuno y Rebollar et al. (2007), la carne de cabra. Jerez et al. (2009) se centran en el caso de los huevos, mientras que Cárcamo (2015) y Rebollar et al. (2011) en el del queso y Engindeniz (2007) en el del tomate.

La problemática de los márgenes de los alimentos va a ser analizada en este trabajo para ver si se da una casuística diferente en los países desarrollados y en los que están en vías de desarrollo desde la perspectiva de la seguridad alimentaria, en lo que sería un enfoque bastante novedoso. En esta línea se pueden destacar trabajos previos interesantes sobre este tema como los de Martuscelli (2008), Morales y Rendón (2008), Trejos (2008), Chávez y Villarreal 
(2009), Driouchi et al. (2009), Cascante (2011), Sánchez y Rodríguez (2013) y Sumpsi (2013). No obstante, estos estudios no analizan los márgenes de precios en sí mismos ni utilizan criterios de seguridad alimentaria en las dimensiones consideradas por la FAO (2016).

En el contraste entre la escasez alimentaria sufrida en los países en vías de desarrollo y la sobreabundancia de los mismos en los países desarrollados, “sociedad de la saciedad” según Díaz (2003), la seguridad alimentaria constituye un punto de debate interesante en los foros y organismos internacionales. Está claro que el derecho a la alimentación se percibe como un derecho fundamental de las personas, llegando a aparecer en múltiples normativas. La Declaración Universal de los Derechos Humanos (1948) lo enuncia como el derecho a disponer de una alimentación suficiente y saludable. El "Libro Blanco sobre Seguridad Alimentaria” de la Comisión de las Comunidades Europeas (2001) establece también que los consumidores deberán tener acceso a una extensa gama de productos seguros y de calidad. Autores como Briz (2011) inciden en que se deben dar en cantidad suficiente y estar en buen estado.

Aun así, el concepto de seguridad alimentaria es una cuestión que puede llevar a equívocos derivados de la dualidad que implica diferenciar la actitud de los países desarrollados y de los países en vías de desarrollo. Langreo (2004) lo explica argumentando que mientras en los países desarrollados este concepto se suele relacionar con el consumo de alimentos sanos, en los segundos hace referencia a la disponibilidad suficiente para la subsistencia humana. De este modo, sería un objetivo clave para la mayoría de las personas, al ubicarse en definitiva, en el contexto de la lucha contra el hambre.

Fernández (2002) considera que este problema dialéctico se debe a que en castellano sólo se utiliza la palabra "seguridad" para dos acepciones bastante distintas. Por ejemplo, en idiomas como el inglés se distingue entre "safety" (estar a salvo de algo) y "security" (tener seguridad acerca de algo). Esto se da también en francés ("sûreté" vs "sécurité") o en alemán ("Ernährungssicherheit" vs "Lebensmittelsicherheit”). Langreo (2004) añade que este desconcierto tiene su origen en una traducción incorrecta del inglés, ya que se podría diferenciar más claramente entre lo que se conoce como salubridad de los alimentos y la seguridad alimentaria de abastecimiento en sí misma. Esta postura es refrendada por McCalla (1997) y Molina (2002) y que será la que se utilice en este artículo.

Díaz (2003) explica que la Organización de las Naciones Unidas para la Alimentación y la Agricultura (En adelante, FAO) afronta este debate definiendo la seguridad alimentaria de abastecimiento como el acceso físico y económico de todas las personas y en todo momento a una cantidad suficiente de alimentos. Briz (2011) añade que la cuestión clave radica en que el bien consumido esté en el lugar, momento y condiciones adecuadas. 
Bajo este planteamiento, se intentará analizar cómo han evolucionado los precios de los alimentos para productores y consumidores, en lo que serían los extremos de la cadena de valor, con respecto al avance o al deterioro de las condiciones de seguridad alimentaria de abastecimiento que ofrecen los países que constituyen la muestra estudiada. Con tal objetivo, tras esta introducción, en primer lugar se ha desarrollado la metodología en el epígrafe que sigue a continuación. Los resultados de este trabajo se estructuran en un tercer apartado en el que se estudia el análisis cluster, según el algoritmo de Howard-Harris, descomponiendo la muestra en tres conglomerados. En el cuarto epígrafe se ha realizado un análisis CHAID. Por último, el trabajo termina exponiendo las principales conclusiones obtenidas, con la discusión de resultados, y las referencias bibliográficas.

\section{METODOLOGÍA DE TRABAJO}

Las variables principales manejadas en este estudio son los índices de Precios Anuales del Consumidor y del Productor, recogidos por la FAO para los años 2000 y 2010, para ver su evolución en la primera década del siglo XXI con datos disponibles. FAO (2016) los define de la siguiente manera:

- El índice de los precios anuales del consumidor utilizado recoge la evolución del nivel general de los precios de los alimentos y bebidas no alcohólicas que los hogares adquieren, usan o pagan por el consumo. Para ello se mide el coste de compra de una cesta fija de alimentos y bebidas de consumo, de calidad constante y características similares, seleccionándose aquellos que sean representativos en un período determinado.

- El índice relativo a los precios anuales del productor mide el cambio medio anual de los precios de venta obtenidos por los agricultores, siendo precios a la salida de la explotación agrícola o en el punto de primera venta. Este índice incluye los cultivos primarios y productos pecuarios producidos en un país y de los que se dispone de datos sobre la producción y los precios del productor. La FAO presenta este índice con período base de 2004-2006, por lo que se han ajustado a base 2000 para facilitar su comparabilidad con los índices de precios de los alimentos al consumidor.

Tras determinarlos, se ha calculado la evolución del diferencial de precios alimentarios calculando en primer lugar el índice en ese período para cada uno de ellos, y dividiendo después el correspondiente a los precios al consumidor entre los del productor. De esta manera, un valor superior a la unidad o positivo, según la referencia, significaría que el diferencial entre ambos agentes ha aumentado, así como una disminución del mismo si el valor obtenido fuera el contrario. Los resultados se muestran en el anexo en la Tabla 8. 
El resto de variables utilizadas en el estudio serían los distintos indicadores de seguridad alimentaria de abastecimiento, que pueden reflejar el nivel de desarrollo económico y social del país. FAO (2016) difunde estadísticas sobre alimentación y seguridad alimentaria en concreto. Suelen ser obtenidas mediante encuestas nacionales por hogares, midiéndose normalmente por persona y por día. En este artículo, los indicadores de seguridad alimentaria también se han recogido como la variación en el período 2000-2010, para compararla con el diferencial de precios. De esta forma, salvo en algunas excepciones, un resultado por encima de la unidad reflejaría una mejora en el desarrollo económico y social. Los indicadores se clasifican en las cuatro dimensiones de la seguridad alimentaria que establece FAO (2016). Sólo se han considerado aquellos que ofrecen una muestra suficiente para el estudio. Sus valores se muestran en la Tabla 9 expuesta en el anexo:

- Indicadores de disponibilidad: FAO (2016) considera que las siguientes variables, habiéndose incluido todas en este estudio:

- Suficiencia de suministro medio de energía alimentaria: Este indicador se calcula como el porcentaje medio de las necesidades de energía alimentaria en cada país, apareciendo normalizado respecto a las necesidades alimentarias estimadas para la población.

- Valor medio de la producción alimentaria: Refleja el valor de la producción total anual de alimentos dividido entre la población total.

- Porcentaje del suministro de energía alimentaria procedente de cereales, raíces y tubérculos: Mide la proporción que representa sobre el total de suministro de energía alimentaria.

- Suministro medio de proteínas.

- Suministro medio de proteínas de origen animal: Incluye el suministro de carne, grasas animales, pescado, leche, despojos, huevos, mariscos y sus derivados.

- Indicadores de acceso: En este grupo se incluye el porcentaje de carreteras pavimentadas sobre el total, su densidad, la densidad de líneas ferrocarril, el índice de precios de los alimentos en el hogar, la cuota de gasto en alimentos de los pobres, la frecuencia de la desnutrición y de insuficiencia alimentaria o la profundidad del déficit de alimentos. Sin embargo, sólo se ha considerado el Producto Interior Bruto per cápita en poder adquisitivo equivalente.

- Indicadores de estabilidad: En este grupo se encuentran estos indicadores:

- Porcentaje de dependencia de importaciones de cereales: Se calcula dividiendo las importaciones de cereales entre el saldo de cereales del 
país, partida que abarca la producción de cereales, más importaciones y menos exportaciones.

- Porcentaje de de tierra de cultivo equipada con sistemas de riego.

- Porcentaje de importaciones de alimentos en relación a las exportaciones totales de mercancías.

- Variabilidad del suministro de alimentos per cápita. Recoge la variabilidad del valor neto de la producción de alimentos por habitante en términos constantes con base 2004-2006, a través de la desviación sobre su tendencia en 1985-2010.

- Otros indicadores no incluidos por insuficiencia de datos, serían la estabilidad política, la ausencia de violencia o terrorismo y la volatilidad de precios de los alimentos y la de la producción de los alimentos por habitante.

- Indicadores de utilización: En esta categoría se han considerado:

- Porcentaje de población con acceso a fuentes mejoradas de agua: Sería el porcentaje de población con acceso a un mínimo de 20 litros de agua por persona al día a un kilómetro de la vivienda como máximo.

- Porcentaje de población que tiene acceso a instalaciones de saneamiento: Sería la población con un acceso adecuado a instalaciones de eliminación de excrementos, que sirvan para prevenir eficazmente a personas, animales e insectos del contacto con ellos.

- Frecuencia de anemia entre mujeres embarazadas. Recoge la proporción de estas mujeres, con hemoglobina inferior a 110 gramos por litro a nivel del mar, por lo que sería insuficiente para asimilar oxígeno y satisfacer las necesidades básicas.

- Frecuencia de anemia entre niños de menos de 5 años de edad: Sería un caso parecido al anterior, pero con datos referidos a este colectivo.

- Otras variables consideradas por la FAO pero no incluidas en trabajo serían el porcentaje de niños menores de 5 años de edad con debilidad, enanismo y bajo peso, variable esta última que también se considera para los adultos.

Respecto a estas variables, inicialmente se han estudiado todos los datos a nivel mundial. Para alcanzar la mayor muestra posible, se han descartado los países y los indicadores con información incompleta en 2000 y 2010. Así, la muestra se ha reducido a 73 países de todo el mundo, que aparecen en las estadísticas de las Tablas 8 y 9A y 9 B en el anexo. Con el objetivo de minimizar el impacto de posibles errores en la estimación, estos indicadores se suelen calcular como una media móvil de los datos en un período de 3 años. Para obtener una visión global, basándose en datos de FAO (2016), la Tabla 1 
destaca los países en todo el mundo con mayores y menores crecimientos en estas variables. Hay un papel especialmente relevante de los países en vías de desarrollo como muestra de los mayores cambios producidos en estas cuestiones.

Tabla 1

Países con mayores y menores crecimientos en las variables objeto de estudio (\%)

\begin{tabular}{|c|c|c|c|c|}
\hline \multirow{2}{*}{$\begin{array}{l}\text { Variable } \\
\begin{array}{l}\text { Diferencial de precios entre productores y } \\
\text { consumidores. }\end{array}\end{array}$} & \multicolumn{2}{|c|}{$\begin{array}{c}\text { Mayores } \\
\text { crecimientos }\end{array}$} & \multicolumn{2}{|c|}{$\begin{array}{c}\text { Menores } \\
\text { crecimientos }\end{array}$} \\
\hline & $\begin{array}{l}\text { Etiopía } \\
\text { Barbados } \\
\text { Hungría } \\
\end{array}$ & $\begin{array}{l}+43,2 \\
+41,9 \\
+30,2\end{array}$ & $\begin{array}{l}\text { Islas Mauricio } \\
\text { Ucrania } \\
\text { Turquía } \\
\end{array}$ & $\begin{array}{l}-77,1 \\
-68.1 \\
-63,3 \\
\end{array}$ \\
\hline $\begin{array}{l}\text { Suficiencia de suministro medio de energía } \\
\text { alimentaria. }\end{array}$ & $\begin{array}{l}\text { Armenia } \\
\text { Ghana } \\
\text { Camerún }\end{array}$ & $\begin{array}{l}+21,1 \\
+18,6 \\
+17,5\end{array}$ & $\begin{array}{l}\text { Namibia } \\
\text { Japón } \\
\text { Colombia }\end{array}$ & $\begin{array}{l}-9,1 \\
-6,7 \\
-5,2\end{array}$ \\
\hline Valor medio de producción alimentaria. & $\begin{array}{l}\text { Armenia } \\
\text { Letonia } \\
\text { Lituania } \\
\end{array}$ & $\begin{array}{l}+83,7 \\
+59,8 \\
+51,8 \\
\end{array}$ & $\begin{array}{l}\text { Chipre } \\
\text { Fiji } \\
\text { Grecia } \\
\end{array}$ & $\begin{array}{l}-33,0 \\
-16,6 \\
-16,3 \\
\end{array}$ \\
\hline $\begin{array}{l}\text { Porcentaje del suministro de energía alimentaria } \\
\text { procedente de cereales, raíces y tubérculos. }\end{array}$ & $\begin{array}{l}\text { Países Bajos } \\
\text { Bélgica } \\
\text { Panamá }\end{array}$ & $\begin{array}{l}+28,6 \\
+15,4 \\
+12,5 \\
\end{array}$ & $\begin{array}{l}\text { Armenia } \\
\text { Moldavia } \\
\text { Lituania } \\
\end{array}$ & $\begin{array}{l}-30,6 \\
-24,6 \\
-20,4 \\
\end{array}$ \\
\hline Suministro de proteínas medio. & $\begin{array}{l}\text { Armenia } \\
\text { Camerún } \\
\text { R. Dominic. }\end{array}$ & $\begin{array}{c}+28,8 \\
+23,6 \\
+23,4 \\
\end{array}$ & $\begin{array}{l}\text { Namibia } \\
\text { Japón } \\
\text { Chipre } \\
\end{array}$ & $\begin{array}{l}-10,6 \\
-8,3 \\
-8,1 \\
\end{array}$ \\
\hline Suministro de proteínas medio de origen animal. & $\begin{array}{l}\text { Armenia } \\
\text { Etiopía } \\
\text { Lituania } \\
\end{array}$ & $\begin{array}{l}+95,0 \\
+60,0 \\
+50,0\end{array}$ & $\begin{array}{l}\text { Namibia } \\
\text { Hungría } \\
\text { Japón }\end{array}$ & $\begin{array}{l}-14,8 \\
-11,8 \\
-10,9 \\
\end{array}$ \\
\hline $\begin{array}{l}\text { Producto interno bruto per cápita (en poder } \\
\text { adquisitivo equivalente). }\end{array}$ & $\begin{array}{l}\text { Armenia } \\
\text { Nigeria } \\
\text { Albania } \\
\end{array}$ & $\begin{array}{l}+123,0 \\
+80,3 \\
+80,0 \\
\end{array}$ & $\begin{array}{l}\text { Madagascar } \\
\text { Malawi } \\
\text { Dinamarca } \\
\end{array}$ & $\begin{array}{l}-4,5 \\
-1,0 \\
+2,1 \\
\end{array}$ \\
\hline $\begin{array}{l}\text { Porcentaje de dependencia de importaciones de } \\
\text { cereales. }\end{array}$ & $\begin{array}{l}\text { Letonia } \\
\text { Hungría } \\
\text { Rumanía } \\
\end{array}$ & $\begin{array}{l}+491,9 \\
+320,0 \\
+188,4 \\
\end{array}$ & $\begin{array}{l}\text { Rusia } \\
\text { Ucrania } \\
\text { Pakistán } \\
\end{array}$ & $\begin{array}{l}-79,5 \\
-70,8 \\
-33,9 \\
\end{array}$ \\
\hline $\begin{array}{l}\text { Porcentaje de tierra de cultivo equipada con } \\
\text { sistemas de riego. }\end{array}$ & $\begin{array}{l}\text { Croacia } \\
\text { Nicaragua } \\
\text { Eslovenia } \\
\end{array}$ & $\begin{array}{l}+525,0 \\
+173,3 \\
+147,4\end{array}$ & $\begin{array}{l}\text { Bulgaria } \\
\text { Reino Unido } \\
\text { Lituania } \\
\end{array}$ & $\begin{array}{l}-81,9 \\
-47,6 \\
-33,3 \\
\end{array}$ \\
\hline $\begin{array}{l}\text { Valor de importaciones de alimentos con respecto a } \\
\text { las exportaciones totales. }\end{array}$ & $\begin{array}{l}\text { Moldavia } \\
\text { Nepal } \\
\text { Panamá } \\
\end{array}$ & $\begin{array}{l}+162,5 \\
+156,5 \\
+144,7\end{array}$ & $\begin{array}{l}\text { Namibia } \\
\text { R. Dominic. } \\
\text { Albania }\end{array}$ & $\begin{array}{l}-66,7 \\
-62,2 \\
-50,7 \\
\end{array}$ \\
\hline Variabilidad del suministro de alimentos per cápita. & $\begin{array}{l}\text { Bélgica } \\
\text { EEUU } \\
\text { Madagascar }\end{array}$ & $\begin{array}{l}+400,0 \\
+293,7 \\
+283,3 \\
\end{array}$ & $\begin{array}{l}\text { Rep. Corea } \\
\text { Croacia } \\
\text { El Salvador }\end{array}$ & $\begin{array}{l}-81,8 \\
-76,1 \\
-72,0 \\
\end{array}$ \\
\hline $\begin{array}{l}\text { Porcentaje de población con acceso a fuentes } \\
\text { mejoradas de agua. }\end{array}$ & $\begin{array}{l}\text { Etiopía } \\
\text { Laos } \\
\text { Malawi } \\
\end{array}$ & $\begin{array}{l}+64,8 \\
+48,3 \\
+30,1 \\
\end{array}$ & $\begin{array}{l}\text { Yemen } \\
\text { Argelia } \\
\text { R. Dominic. }\end{array}$ & $\begin{array}{l}-8,9 \\
-6,3 \\
-4,7 \\
\end{array}$ \\
\hline $\begin{array}{l}\text { Porcentaje de población que con acceso a } \\
\text { instalaciones de saneamiento. }\end{array}$ & $\begin{array}{l}\text { Etiopía } \\
\text { Laos } \\
\text { Nepal } \\
\end{array}$ & $\begin{array}{l}+157,3 \\
+109,6 \\
+65,5\end{array}$ & $\begin{array}{l}\text { Nigeria } \\
\text { F. Rusia } \\
\text { Ucrania }\end{array}$ & $\begin{array}{l}-12,3 \\
-2,4 \\
-0,8 \\
\end{array}$ \\
\hline Frecuencia de anemia entre mujeres embarazadas. & $\begin{array}{l}\text { EEUU } \\
\text { Armenia } \\
\text { Reino Unido } \\
\end{array}$ & $\begin{array}{l}+24,2 \\
+21,4 \\
+10,9 \\
\end{array}$ & $\begin{array}{l}\text { Etiopía } \\
\text { Filipinas } \\
\text { México } \\
\end{array}$ & $\begin{array}{l}-33,2 \\
-27,1 \\
-26,5 \\
\end{array}$ \\
\hline $\begin{array}{l}\text { Frecuencia de anemia entre niños menores de } 5 \\
\text { años. }\end{array}$ & $\begin{array}{l}\text { El Salvador } \\
\text { Rep. Corea } \\
\text { Egipto }\end{array}$ & $\begin{array}{l}+44,7 \\
+34,3 \\
+28,2\end{array}$ & $\begin{array}{l}\text { Nicaragua } \\
\text { Madagascar } \\
\text { Indonesia }\end{array}$ & $\begin{array}{l}-44,1 \\
-23,6 \\
-22,6\end{array}$ \\
\hline
\end{tabular}

Fuente: Elaboración propia según datos de FAO (2016). 
Se han realizado estos análisis siguiendo a Santesmases (2005):

- El análisis CHAID (Chi Square Automatic Interaction Detection) es un método que estudia las posibles dependencias entre una variable dependiente o criterio y otras predictoras o independientes, escogiendo la combinación que tiene el nivel de significación más alto de su $\mathrm{X}^{2}$ de Pearson. Presenta el resultado obtenido en forma de diagrama de árbol, donde se establece qué variables son las más discriminantes con la variable dependiente y en qué secuencia lo llevan a cabo. En el análisis realizado, el tamaño mínimo del segmento exigido para su división posterior es de 15 elementos, con un 5\% de nivel mínimo de significación en su partición. La variable que se va a explicar es la evolución del diferencial de precios alimentarios entre productores y consumidores en el período 2000-2010.

- El análisis cluster es un conjunto de herramientas estadísticas que ayudan a determinar unos grupos homogéneos internamente, aunque diferentes entre sí, por división de segmentos más grandes o por agrupación de unidades más pequeñas, según una selección previa de bases o criterios de la segmentación (García, 2008). La utilización de este análisis tiene ciertos problemas como la determinación del número de grupos que se deben retener, la elección de la medida de similitud, y, en algunos casos, se deben realizar un gran número de operaciones que exigen con frecuencia el uso de variables métricas.

Existen varias técnicas de análisis cluster, ya sean ascendentes (building up), que generan los grupos por agregación a partir de las observaciones, o descendentes (breaking down), que parten del total de elementos y lo dividen en grupos más pequeños. Entre las distintas técnicas descendentes, se ha utilizado el algoritmo de Howard-Harris con una agrupación de 3 clusters, ya que a diferencia del resto de técnicas, ésta se puede aplicar a muestras grandes (Santesmases, 2005). Además, tras haber probado con otras técnicas como los algoritmos de K-medias o de Johnson, y con distinto número de conglomerados, el análisis que se presenta es el que produce una información de más calidad.

- Se ha utilizado el análisis discriminante, una técnica multivariable que intenta explicar la pertenencia de objetos a grupos concretos. Sería un caso específico de análisis de dependencias entre una variable, que mide o no la pertenencia a una categoría, y una o varias explicativas, para predecir la probabilidad de pertenencia de un elemento a un grupo. Para poder comparar esta asignación a los grupos, que ha sido estimada a través de funciones discriminantes, se utiliza una matriz de confusión, una tabla de doble entrada cuyas filas muestran la pertenencia real al grupo, mientras que las columnas reflejan la estimada por el análisis discriminante. Los posibles aciertos de las funciones discriminantes aparecen en los valores de 
la diagonal principal, calculando el porcentaje de aciertos dividiendo la suma de los casos de esta diagonal entre el número total.

- Por último, se ha calculado el valor del lambda de Wilks, una medida de las diferencias entre grupos que compara la dispersión intragrupo con la dispersión total para la muestra. El nivel global de significación se calcula mediante la $\mathrm{F}$ de Snedecor y el test de Bartlett, una prueba propia del análisis factorial que contrasta la hipótesis de que la matriz de correlación es una matriz de identidad, en la que los términos de la diagonal principal son 1 y el resto 0 . Si se rechaza esta hipótesis, se puede utilizar este análisis. Los valores de este estadístico están entre 0 y 1 :

- Un valor próximo a 0 significa que la variable estudiada separa los grupos de manera correcta, siendo la variabilidad intragrupo muy reducida. Así, se rechazaría la hipótesis nula de igualdad de medias entre los grupos.

- Un valor próximo a 1 implica que la variación dentro de los grupos y la total son muy parecidas, no siendo la variable considerada por tanto una buena variable discriminante. El valor obtenido se deberá a las diferencias dentro de los grupos, estando éstos poco separados de manera que se pueden confundir.

A continuación, se exponen los resultados obtenidos en el análisis.

\section{ANÁLISIS CHAID DE LA EVOLUCIÓN DEL DIFERENCIAL DE PRECIOS AGROALIMENTARIOS ENTRE PRODUCTORES Y CONSUMIDORES.}

En este epígrafe se ha realizado un análisis CHAID tomando como variable principal la evolución del diferencial de precios agroalimentarios entre productores y consumidores, siendo explicativas el resto de las variables. De esta forma se estaría ante un modelo completo ya que se analizan todas las variables utilizadas en esta investigación. El dendrograma obtenido, que se muestra en la Figura 1, ayuda a desarrollar un análisis de dependencias con los segmentos finales generados mediante el test $\mathrm{X}^{2}$. Se puede comprobar que con ellos se podría rechazar la hipótesis de independencia con la variable principal a un nivel del $1 \%$.

En este dendrograma se manifiesta que la muestra se ha clasificado en tres categorías según la variable que mide valor medio de la producción alimentaria, por ser la combinación resultante que tiene un $\mathrm{X}^{2}$ más significativo $(\mathrm{p}=0,0010)$. Entrando en más detalle, se puede extraer como conclusión importante que éstos presentan una disminución en el diferencial de precios entre estos agentes a medida que se incrementa esta variable explicativa. De esta forma, se puede comprobar entonces cómo conforme la valoración de la producción agroalimen- 
taria es más estable, el diferencial de precios crece en mayor medida. Esto se produce incluso cuando esta valoración disminuye, lo cual sería más característico de los países desarrollados. El desglose por segmentos sería:

- El "Valor medio de la producción alimentaria" se mantiene estable o disminuye: Los países que están en este colectivo han visto cómo de promedio, la diferencia entre los precios alimentarios entre productores y consumidores han aumentado un 7,83 \%. Este grupo se puede subdividir a su vez en dos subgrupos según cómo ha evolucionado la frecuencia en el que se dan casos de anemia entre mujeres embarazadas, lo que produciría el $\mathrm{X}^{2}$ más significativo $(\mathrm{p}=0,0428)$ :

- La "Frecuencia de anemia entre mujeres embarazadas" baja (Grupo 2): Los países que se encuentran en este colectivo han experimentado un crecimiento muy importante en la evolución de su diferencial de precios, al haber aumentado un 12,75 \%. En este grupo de países estarían sobre todo países europeos (Eslovaquia, Eslovenia, Hungría, Rep. Checa, Bulgaria y Portugal), de África (Madagascar, Namibia y Nigeria) y de América (Panamá y Barbados).

Figura 1

Análisis CHAID sobre la evolución del diferencial de precios alimentarios según indicadores de seguridad alimentaria de abastecimiento

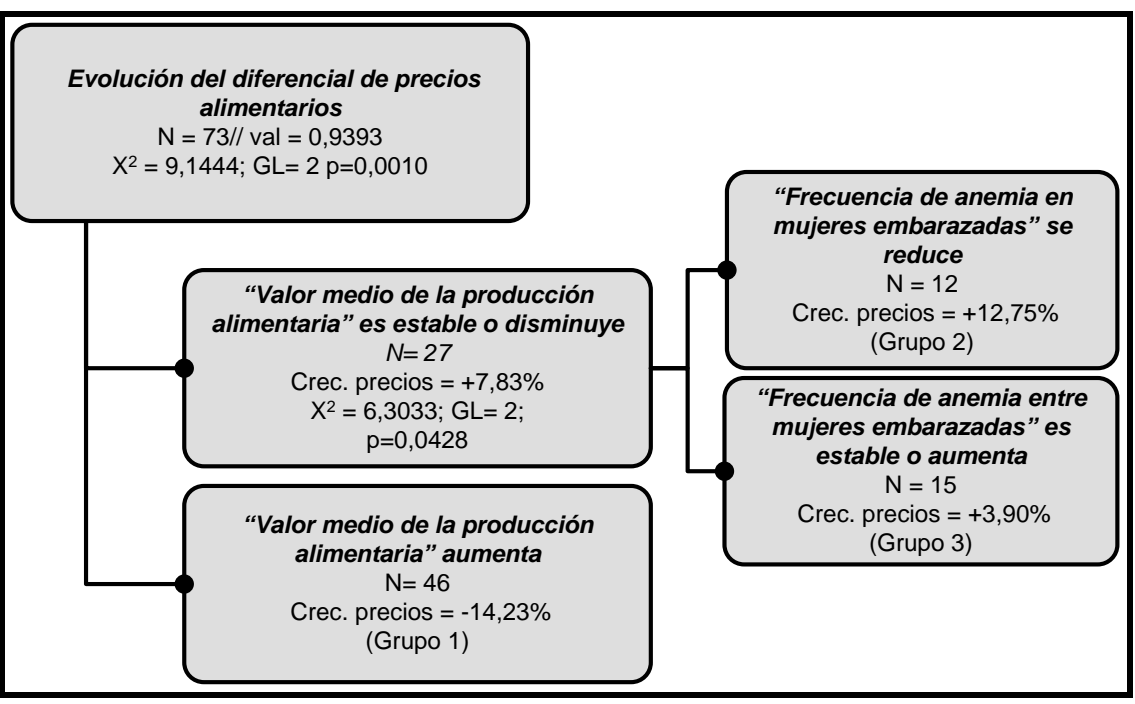

Fuente: Elaboración propia según datos de FAO (2016).

- La "Frecuencia de anemia entre mujeres embarazadas" es estable o aumenta (Grupo 3): Estos países han tenido un incremento menor del diferencial de precios, creciendo sólo un 3,90\%. Es notorio que en esta 
fracción estarían los países más desarrollados, como son los occidentales europeos (Austria, Bélgica, Chipre, España, Finlandia, Francia, Grecia, Malta, Noruega, Reino Unido, Suecia y Suiza), y otros como Australia y Japón. En la mayoría de ellos, este indicador se mantiene relativamente estable. No obstante, para los casos en los que crece, esto se puede deber a que al tratarse de un indicador de baja magnitud en estos países, un pequeño cambio absoluto en el mismo puede suponer una variación porcentual elevada.

- El "Valor medio de la producción alimentaria" aumenta (Grupo 1): Este colectivo es el único que ha tenido una reducción en su diferencial de precios alimentarios, con una caída media del 14,23\%. En este grupo destaca especialmente la mayor participación de países en vías de desarrollo, tanto de África (Argelia, Botswana, Cabo Verde, Camerún, Egipto, Etiopía, Ghana, Islas Mauricio, Malawi, Sudáfrica y Túnez), América (Brasil, Colombia, Ecuador, El Salvador, Honduras, México, Nicaragua y República Dominicana), Asia (Bangladesh, Filipinas, Indonesia, Irán, Jordania, Laos, Nepal, Pakistán, Tailandia, Ucrania y Yemen) y Europa (Con abundancia de países del Este: Albania, Armenia, Rusia, Estonia, Letonia, Lituania, Moldavia, Rumanía y Turquía).

Tabla 2

Estudio de otras variables según los grupos obtenidos en el análisis CHAID.

\begin{tabular}{|l|c|c|c|c|}
\hline & Grupo 1 & Grupo 2 & Grupo 3 & ANOVA / F Snedecor \\
\hline $\begin{array}{l}\text { Suficiencia de suministro medio de } \\
\text { energía alimentaria. }\end{array}$ & $6 \%$ & $2,39 \%$ & $-0,13 \%$ & $\begin{array}{c}\mathrm{F}(2,70)=6,6138 \\
\mathrm{p}=0,0023\end{array}$ \\
\hline Valor medio de la producción alimentaria. & $24,27 \%$ & $-6,3 \%$ & $-9,86 \%$ & $\begin{array}{c}\mathrm{F}(2,70)=41,8252 \\
\mathrm{p}=0,0000\end{array}$ \\
\hline Suministro de proteínas medio. & $10,54 \%$ & $1,53 \%$ & $-0,50 \%$ & $\begin{array}{c}\mathrm{F}(2,70)=15,1026 \\
\mathrm{p}=0,0000\end{array}$ \\
\hline $\begin{array}{l}\text { Suministro de proteínas medio de origen } \\
\text { animal. }\end{array}$ & $24,10 \%$ & $0,72 \%$ & $-0,20 \%$ & $\begin{array}{c}\mathrm{F}(2,70)=17,2940 \\
\mathrm{p}=0,0000\end{array}$ \\
\hline $\begin{array}{l}\text { Producto Interior Bruto per cápita (en } \\
\text { poder adquisitivo equivalente). }\end{array}$ & $37,19 \%$ & $32,43 \%$ & $13,02 \%$ & $\begin{array}{c}\mathrm{F}(2,70)=5,9769 \\
\mathrm{p}=0,0040\end{array}$ \\
\hline
\end{tabular}

Fuente: Elaboración propia según datos de FAO (2016).

En este análisis se puede comprobar por lo tanto cómo, con el estudio de la variable que mide la evolución del diferencial de precios alimentarios en el período 2000-2010, se verifica que conforme aumenta el valor medio de la producción alimentaria se ha ido reduciendo el diferencial de precios entre consumidores y productores. De esta manera, la Tabla 2 recoge cómo mejoran otras variables de seguridad alimentaria de abastecimiento según si el conjunto resultante en el análisis CHAID tiene un mayor o menor desarrollo económico. En esta tabla se muestran únicamente 
aquellos indicadores que poseen resultados significativos según la prueba F de Snedecor, siéndolo todos ellos a un nivel del 1\%.

En conclusión, se puede terminar este epígrafe destacando que es el grupo 1, aquel en el que hay un mayor número de países en vías en desarrollo, el que muestra mayores crecimientos medios. Se debe resaltar sobre todo el crecimiento del Producto Interior Bruto per cápita (Con un 37,19\% de promedio) y la variación del valor medio de la producción alimentaria y del suministro de proteínas medio de origen animal (Con un 24\% cada grupo). Estos porcentajes se van reduciendo progresivamente hasta los ofrecidos por el grupo 3, en el que predominan principalmente los países occidentales.

\section{ANÁLISIS CLUSTER DE LA EVOLUCIÓN DEL DIFERENCIAL DE PRECIOS AGROALIMENTARIOS ENTRE PRODUCTORES Y CONSUMIDORES.}

En este apartado se realizará un análisis de clusters o conglomerados a las variables objeto de estudio, referidas a los países del mundo que componen la muestra, siguiendo el algoritmo de Howard-Harris, con 3 clusters. En primer lugar, se van a explicar algunos indicadores que complementan y justifican el análisis realizado. De entrada, la estimación de la suma de cuadrados que viene explicada por la partición en grupos de la muestra para este análisis ascendería a un 61,50 \%, superando así el 50\%, con una suma de cuadrados del total de la muestra de 11,69 e intragrupos para todos los grupos de 4,50. Además, el incremento de la varianza explicada respecto al número inmediatamente superior de cluster es inferior o igual al 5\%, según se ha incluido en la configuración inicial del análisis.

El indicador Lambda de Wilks de los clusters generados asciende a 0,1561, para una F de Snedecor de 20,2055, con 10 y 132 grados de libertad. Se puede afirmar entonces que las diferencias entre los grupos obtenidos son destacables por estar sus valores bastante próximos a 0 , con lo que los centros de los grupos serían claramente diferentes. Como la p sería igual a 0,0000, los grupos obtenidos en el análisis sí se diferenciarían por las variables utilizadas a un nivel del $1 \%$.

A continuación se expone el análisis cluster realizado según el algoritmo de Howard-Harris y partiendo de los datos presentados en la metodología. Entre las variables elegidas se ha seleccionado aquella que mide la evolución del diferencial de precios alimentarios entre productores y consumidores, así como todas las variables relativas a la seguridad alimentaria de abastecimiento. El análisis de las medias obtenidas, que se muestran en la Tabla 3, permite definir las características comunes de los países de cada cluster. 
Tabla 3

Análisis cluster de las variables estudiadas

\begin{tabular}{|l|c|c|c|c|c|c|}
\hline & & Media & C. 1. & C. 2. & C. 3. & \\
\cline { 2 - 6 } & No elem. & $\mathbf{7 3}$ & $\mathbf{1 4}$ & $\mathbf{2 9}$ & $\mathbf{3 0}$ & \\
\hline Variables & $\begin{array}{c}\text { Suma } \\
\text { cuadrados }\end{array}$ & $11,69 \%$ & $1,58 \%$ & $2,16 \%$ & $0,76 \%$ & \multirow{2}{*}{ ANOVA } \\
\hline $\begin{array}{l}\text { Suficiencia de suministro } \\
\text { medio de energía alim. }\end{array}$ & Media: & $+4,15 \%$ & $+9,47 \% \uparrow$ & $+6,14 \%$ & $-0,27 \% \downarrow$ & $F(2,70)=20,7369$ \\
\hline & Des. Est.: & 0,06 & 0,05 & 0,06 & 0,04 & $p=0,0000$ \\
\hline $\begin{array}{l}\text { Valor medio de la producción } \\
\text { alimentaria. }\end{array}$ & Media: & $+12,23 \%$ & $+36,76 \% \uparrow$ & $+18,69 \%$ & $-0,46 \% \downarrow$ & $F(2,70)=46,7427$ \\
\hline & Des. Est.: & 0,21 & 0,20 & 0,15 & 0,09 & $p=0,0000$ \\
\hline $\begin{array}{l}\text { Suministro de proteínas } \\
\text { medio. }\end{array}$ & Media: & $+6,79 \%$ & $+14,85 \% \uparrow$ & $+10,23 \%$ & $-0,29 \% \downarrow$ & $F(2,70)=30,7214$ \\
\hline & Des. Est.: & 0,09 & 0,07 & 0,08 & 0,05 & $p=0,0000$ \\
\hline $\begin{array}{l}\text { Suministro de proteínas } \\
\text { medio de origen animal. }\end{array}$ & Media: & $15,27 \%$ & $+40,08 \% \uparrow$ & $+19,91 \%$ & $-0,80 \% \downarrow$ & $F(2,70)=47,9655$ \\
\hline & Des. Est.: & 0,20 & 0,19 & 0,14 & 0,07 & $p=0,0000$ \\
\hline $\begin{array}{l}\text { PIB per cápita (en poder } \\
\text { adquisitivo equivalente). }\end{array}$ & Media: & $+31,44 \%$ & $+70,25 \% \uparrow$ & $+32,45 \%$ & $+12,36 \% \downarrow$ & $F(2,70)=83,7866$ \\
\hline & Des. Est.: & 0,25 & 0,17 & 0,15 & 0,10 & $p=0,0000$ \\
\hline
\end{tabular}

* Las flechas $(\uparrow y \downarrow)$ reflejan respectivamente que el valor es el mayor y el menor de los tres grupos obtenidos.

Fuente: Elaboración propia según datos de FAO (2016).

Obsérvese que los indicadores que aparecen pertenecen al grupo de disponibilidad y acceso, no habiendo ninguno de estabilidad o utilización. En este cuadro se puede observar que todos los tests $\mathrm{F}$ de Snedecor presentados rechazan la hipótesis de igualdad de las medias a un nivel del 1\% ( $\mathrm{p}=0,0000)$, lo que implica que las diferencias entre los valores medios son significativas a ese nivel y que habrá al menos un grupo con una media distinta de la de los demás conglomerados obtenidos. De esta forma cada uno de los factores tendría un comportamiento distinto con respecto a cada uno de los conglomerados. En definitiva, como se aprecia en dicha Tabla 3, los clusters obtenidos serían los siguientes:

- Conglomerado número 1, que abarca 14 de los 73 países de la muestra: Este cluster se configura como el que tiene la visión más positiva de los tres obtenidos sobre las variables utilizadas. Se podría caracterizar entonces como el cluster óptimo, ya que todas las variables de seguridad alimentaria han experimentado incrementos importantes, que oscilan entre el 9,47\% del crecimiento del suministro medio de energía hasta el del Producto Interior Bruto per cápita, que crece un 70,25\%.

Es reseñable también que, como muestra la Tabla 4, el diferencial de precios agroalimentarios se habría reducido un 5,90\% de media en este cluster. Esto se correspondería con una importante mejoría en su desarrollo económico atendiendo a criterios de seguridad alimentaria de abastecimiento. Se debe 
destacar que en este cluster aparecen muchos países frecuentemente calificados como de "en vías de desarrollo", con mucha presencia de democracias recientes a nivel mundial. Así, entre los países europeos aparecen sobre todo países del Este de Europa (Albania, Armenia, Letonia, Lituania, Moldavia, Rumanía, Rusia y Ucrania), Asia (Bangladés, Indonesia y Laos) y África (Cabo Verde, Etiopía y Nigeria). En este cuadro se muestra igualmente cómo estos países son los que han visto reducida en mayor medida la frecuencia de anemia en mujeres y niños menores de 5 años.

Tabla 4

Tabulación de valores medios para las demás variables*

\begin{tabular}{|l|c|c|c|c|}
\hline & C. 1. & C. 2. & C. 3. & $\begin{array}{c}\text { ANOVA I } \\
\text { F Snedecor }\end{array}$ \\
\hline $\begin{array}{l}\text { Evolución del diferencial de precios } \\
\text { alimentarios. }\end{array}$ & $-5,90 \%$ & $-17,25 \%$ & $+4,66 \%$ & $\begin{array}{c}\mathrm{F}(2,70)=5,9753 \\
\mathrm{p}=0,0040\end{array}$ \\
\hline $\begin{array}{l}\text { Frecuencia de anemia en mujeres } \\
\text { embarazadas. }\end{array}$ & $-11,98 \%$ & $-11,73 \%$ & $-2,67 \%$ & $\begin{array}{c}\mathrm{F}(2,70)=6,9251 \\
\mathrm{p}=0,0018\end{array}$ \\
\hline $\begin{array}{l}\text { Frecuencia de anemia en niños } \\
\text { menores de 5 años. }\end{array}$ & $-5,96 \%$ & $+1,54 \%$ & $+6,44 \%$ & $\begin{array}{c}\mathrm{F}(2,70)=3,6885 \\
\mathrm{p}=0,0300\end{array}$ \\
\hline
\end{tabular}

*Sólo se consideran los valores representativos según la F de Snedecor.

Fuente: Elaboración propia según datos de FAO (2016).

- Conglomerado número 2, que incluye 29 de los 73 países que componen la muestra: Según los valores de los indicadores de este cluster se han producido mejoras muy positivas en seguridad alimentaria, con crecimientos que oscilan entre el 6,14 \% del suministro medio de energía hasta el 32,45 \% del Producto Interior Bruto per cápita. No obstante, se debe comentar también que todos estos valores serían inferiores a los del cluster 1 , siendo incluso la mitad de su magnitud en 3 de las 5 magnitudes estudiadas.

Se debe añadir también que, en este caso, el diferencial de precios habría disminuido un $17,25 \%$, la mayor reducción de todos los cluster, como se aprecia en la Tabla 3. De esta forma, esta disminución también se correspondería con mejoras destacables en los distintos indicadores de seguridad alimentaria analizados. En este conglomerado vuelve a tener un peso importante de los países en vías de desarrollo sobre todo en los casos de América (Brasil, Ecuador, El Salvador, Honduras, Nicaragua, Panamá y República Dominicana), África (Argelia, Botswana, Camerún, Egipto, Ghana, Islas Mauricio, Malawi, Sudáfrica, Túnez y Yemen) y Asia (Filipinas, Irán, Jordania, Nepal, Pakistán, República de Corea y Tailandia). La relativamente escasa presencia de países europeos se limita a países del Este (Bulgaria, Croacia, Eslovaquia, Estonia y Turquía).

Por último, para terminar con este cluster, en la citada Tabla 3 aparece que en él disminuye también la frecuencia con la que se ha producido anemia entre 
mujeres, aunque no tanto como se daba en el cluster 1. Este peor dato se produce si se analizan los casos de anemia en los niños menores de 5 años, en los que se ha producido incluso un ligero incremento.

- Conglomerado número 3, que abarca 30 de los 73 países de la muestra: Estos países tienen unas evoluciones muy estables de los cuatro primeros índices en el periodo 2000-2010, al tener valores muy cercanos a 0. Sólo presentan un crecimiento destacable del $12,36 \%$ en la evolución del PIB per cápita. No obstante, en cualquier caso, los valores son los más bajos de los tres clusters obtenidos.

Como aparece recogido en la Tabla 3, se debe destacar también que en este cluster el diferencial de precios alimentarios habría crecido un 4,66\% de promedio, siendo el único en el que ha habido esta evolución. Es reseñable que la mayor parte de los países incluidos en este grupo son países calificados comúnmente como "países desarrollados", destacando especialmente la presencia de todos los países de Europa Occidental, Canadá, Estados Unidos de América, Japón y Australia. En dicho cuadro se comprueba además que este cluster es en el que menos ha disminuido la frecuencia de anemias en mujeres, aunque ha aumentado en el caso de los niños menores de 5 años, siendo el único grupo en el que esto ha sucedido.

El test $\mathrm{X}^{2}$ de Bartlett realizado obtiene una $\mathrm{p}=0,0000$, para una $\mathrm{X}^{2}$ igual a 126,2764 y 10 grados de libertad. Este indicador permitiría rechazar la hipótesis nula de no correlación significativa, lo que implica que la matriz de correlaciones de la población objeto de estudio no será la identidad. Los datos serían adecuados para poder realizar el análisis factorial de componentes principales y obtener la matriz de confusión de los resultados, para validar la formación de los clusters obtenidos. Esta matriz se obtiene a través de un análisis discriminante, en el que se toma como variable dependiente la variable categórica que identificaría el conglomerado al que pertenece cada país, mientras que las variables independientes serían aquellas que se han utilizado en el análisis cluster, con probabilidades previas iguales para cada grupo. La matriz se muestra en la Tabla 5:

Tabla 5

Matriz de confusión obtenida de los clusters generados en el análisis

\begin{tabular}{|c|c|c|c|c|}
\hline Grupos reales & Cluster $\mathbf{1}$ & Cluster $\mathbf{2}$ & Cluster $\mathbf{3}$ & Total \\
\hline 1 & 14 & 0 & 0 & 14 \\
\hline 2 & 0 & 29 & 0 & 29 \\
\hline 3 & 0 & 0 & 30 & 30 \\
\hline Total & 14 & 29 & 30 & 73 \\
\hline
\end{tabular}

Fuente: Elaboración propia.

En dicha tabla se comprueba que el porcentaje de aciertos en las asignaciones 
producidas por las funciones discriminantes es de un $100 \%$, lo que supone una asignación prácticamente perfecta. Esto podría garantizar que se podrá asignar cualquier país a su grupo correspondiente sólo con conocer sus distintos indicadores. Los valores de las funciones discriminantes generadas según los centroides obtenidos se muestran en la Tabla 6, siendo la pertenencia a esos grupos la variable criterio.

\section{Tabla 6}

Valores de las funciones en los distintos centroides de los grupos

\begin{tabular}{|c|c|c|}
\hline & Función 1 & Función 2 \\
\hline Cluster 1 & 3,6707 & -0.3779 \\
\hline Cluster 2 & 0,4306 & 0,4134 \\
\hline Cluster 3 & $-2,1293$ & $-0,2232$ \\
\hline
\end{tabular}

Fuente: Elaboración propia.

En la Tabla 7 se recogen los coeficientes estandarizados de las funciones discriminantes canónicas y las correlaciones entre las variables con dichas funciones.

Tabla 7

Otros indicadores analizados

\begin{tabular}{|l|c|c|c|c|}
\hline \multirow{2}{*}{} & \multicolumn{2}{|c|}{$\begin{array}{c}\text { Coeficientes } \\
\text { estandarizados }\end{array}$} & \multicolumn{2}{c|}{ Correlaciones } \\
\cline { 2 - 5 } & Función 1 & Función 2 & Función 1 & Función 2 \\
\hline $\begin{array}{l}\text { Suficiencia de suministro medio de energía } \\
\text { alimentaria. }\end{array}$ & $-0,1201$ & $-0,0249$ & $0,6480^{*}$ & 0,4880 \\
\hline Valor medio de la producción alimentaria. & 0,3738 & 0,3134 & $0,8211^{*}$ & 0,3802 \\
\hline Suministro de proteínas medio. & 0,2499 & 0,8127 & $0,7177^{*}$ & 0,6280 \\
\hline Suministro de proteínas medio de origen animal. & 0,3519 & $-0,2913$ & $0,8374^{*}$ & 0,1954 \\
\hline $\begin{array}{l}\text { Producto Interior Bruto per cápita (en poder } \\
\text { adquisitivo equivalente). }\end{array}$ & 0,7823 & $-0,4722$ & $0,9173^{*}$ & $-0,3220$ \\
\hline * Mayor correlación absoluta entre cada variable y las funciones discriminantes & & \\
\hline
\end{tabular}

Fuente: Elaboración propia.

Por último, la representación gráfica bajo dos ejes cualesquiera de los centroides obtenidos, y aplicando las técnicas de análisis discriminante múltiple que se acaba de ver, aparece recogida en la Figura 2.

\section{DISCUSIÓN Y CONCLUSIONES FINALES}

Después de haber presentado las conclusiones de los análisis CHAID y cluster realizados, se puede confirmar finalmente la estrecha relación existente entre la evolución del diferencial de precios alimentarios y la de los indicadores de seguridad alimentaria de abastecimiento en el periodo 2000-2010, ratificando algunas conclusiones de autores como Morales y Rendón (2008). De entrada, se 
puede comprobar cómo en los denominados países desarrollados (Esto es, Europa Occidental, Estados Unidos, Japón y Canadá principalmente), estos indicadores de seguridad alimentaria permanecen estables, con valores muy cercanos a 0, en la mayoría de los casos (Salvo en el Producto Interior Bruto per cápita), mientras que su diferencial de precios alimentarios entre consumidores y productores aumenta muy por encima del promedio mundial.

Figura 2

Representación gráfica de los centroides obtenidos

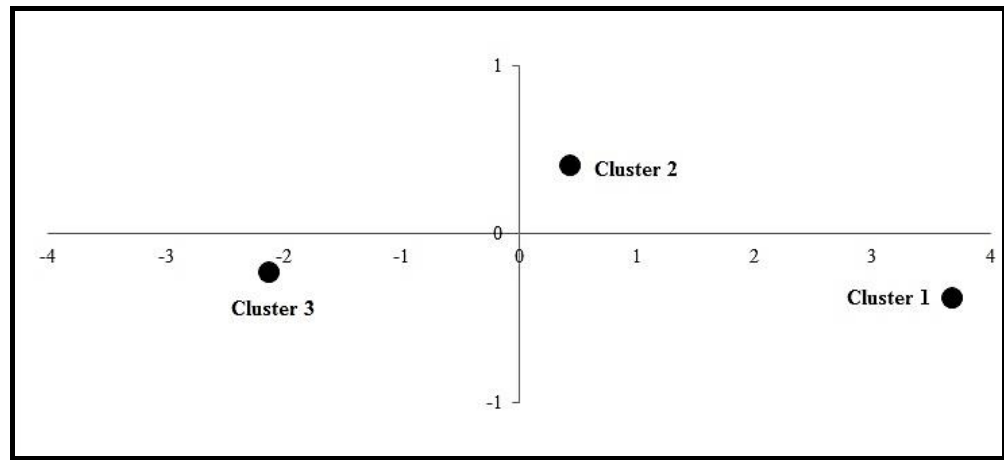

Fuente: Elaboración propia.

Los países en vías de desarrollo presentan una casuística bastante diferente, siguiendo las conclusiones parciales de Masturcelli (2008): Los márgenes alimentarios disminuyen entre consumidores y productores, todo ello ante relevantes progresos en sus condiciones de seguridad alimentaria de abastecimiento. A pesar de ello, se debe puntualizar la existencia de dos posiciones bastante claras atendiendo al análisis cluster, en el que el diferencial de precios disminuye y los indicadores de seguridad alimentaria mejoran:

- En un primer grupo destaca principalmente la mejora de la seguridad alimentaria. En este colectivo habría una importante presencia de países de Europa del Este.

- En el segundo grupo se debe resaltar en mayor medida la reducción de precios entre consumidores y productores (Un 17,25\% mientras que en el caso anterior era de un 5,90\%). En este grupo destacarían los países de África, Asia y Sudamérica.

En general, se aprecia una mejora casi generalizada en los distintos indicadores de seguridad alimentaria analizados en los países que componen la muestra, reduciéndose la brecha entre países desarrollados y en vías de desarrollo. Esta postura es refrendada por trabajos previos como Jordá et al. (2014). El estado del capital físico y humano se vuelve a revelar como muy relevante para el crecimiento, como concluyen los trabajos de Dabús y Laumann (2006) y 
Driouchi et al. (2009), entre otros. No obstante, la mejora experimentada y las ayudas recibidas por estos países son bastante insuficientes (Pérez de Armiño, 2009).

Se puede concluir en definitiva, afirmando que a nivel global la reducción del diferencial de precios entre consumidores y productores agroalimentarios, sería un factor primordial de colaboración en la lucha contra el hambre, y más ampliamente, contra la pobreza. En un último punto, se debe destacar también que de las cuatro dimensiones características de la seguridad alimentaria de abastecimiento (Disponibilidad, acceso, estabilidad y utilización), son los indicadores relativos a la "Disponibilidad" los que han mostrado una vinculación más fuerte con la evolución del diferencial de precios. En cambio, no aparece como relevante ninguna variable de la dimensión "Estabilidad" dentro de los resultados obtenidos. Se puede definir de esta manera con vistas al futuro una posible línea de investigación muy interesante para seguir progresando en estas cuestiones tan importantes en economía y desarrollo humano.

Los resultados obtenidos en este trabajo intentan servir de guía para las políticas económicas y sociales que pretenden mejorar el desarrollo humano de los países. La cooperación internacional en la actualidad se hace por lo tanto más importante aún en estos temas para mejorar la situación del más débil y reducir las asimetrías existentes, en la línea que marcan McCalla (1997), Molina (2002) y Tugores (2014), y sin olvidar las características actuales de los mercados (Arias, 2008). Las distintas acciones deben hacerse concienzudamente ya que como explican Fontela y Guzmán (2003), una mala acción puede incluso empeorar la situación. Estos autores añaden que no se debe olvidar que en última instancia son los propios países en vías de desarrollo los que deberían encontrar sus soluciones para funcionar mejor y generar más riqueza, necesitando reactivar sus producciones agrarias nacionales (Kéfi, 2008).

\section{REFERENCIAS BIBLIOGRÁFICAS}

AMARILLO, F. (2004). "Los precios de los alimentos". Temas para el debate, 110, pp. 1718.

ARSLAN, A. (2011). "Incremento del precio de los alimentos: hechos, causas y expectativas". Temas para el debate, 161, pp. 45-47.

ATANCE, I. y GARCÍA, J.M. (2008). "La evolución de los mercados agrícolas internacionales y su influencia en los precios de los alimentos". Boletín económico de ICE, Información Comercial Española, 2935, pp. 11-22.

ARIAS, P. (2008). "La globalización y el comercio agrícola". Temas para el debate, 161, pp. 67-69.

BELLEMARE, M. (2015). "Rising food prices, food price volatility, and social unrest". American Journal of Agricultural Economics, 97.1, pp. 1-21. 
BRAMBILA, J.; MORA, J.S.; ROJAS, M.M. y PÉREZ, V. (2013). "El precio mínimo al productor primario de leche para reducir las importaciones de lácteos en México". Agrociencia, Vol. 47, №. 5, pp. 511-522.

BRIZ, J. (2011). "Seguridad Alimentaria y nuevas tecnologías en la era de la información". En Briz, J. (Coord). Internet, trazabilidad y seguridad alimentaria (pp. 101-146). Madrid: Ed Mundi-Prensa.

CÁRCAMO, W.I. (2015). "La cadena de mercadeo del queso de la Cooperativa Agroindustria Masiguito R.L.". REICE: Revista Electrónica de Investigación en Ciencias Económicas, Vol. 3, №. 6, pp. 216-237.

CASADEVALL, F. (2011). "Los precios de los alimentos. Un nuevo equilibrio internacional". Cuadernos de Información económica, 223, pp. 61-65.

CASCANTE, K. (2011). "Crisis alimentaria: Un consenso por la agricultura". Política exterior, 25, 142, pp. 127-137.

CASCANTE, K. (2012). "La especulación financiera sobre los precios de los alimentos". Economía exterior: Estudios de la revista Política Exterior sobre la internacionalización de la economía española, 60, pp. 131-139.

CAVERO, T. (2008). "Precios de los alimentos y países en desarrollo: consecuencias y soluciones en un mundo globalizado". En Federación de Cajas de Ahorros VascoNavarra. (Coord). La globalización en el siglo XXI: Retos y dilemas (pp. 85-106). Vitoria: Ed Federación de Cajas de Ahorros Vasco-Navarras.

CHÁVEZ, J. y VILLARREAL, H.J. (2009). "Efecto del incremento en el precio de los alimentos en la pobreza de México". El trimestre económico, 303, pp. 775-805.

COMISIÓN DE LAS COMUNIDADES EUROPEAS (2001). Libro blanco de la Seguridad Alimentaria. Bruselas: Unión Europea.

DABÚS, C. y LAUMANN, Y. (2006). "Determinantes del crecimiento: Evidencia comparada de países con diferente nivel de desarrollo". Estudios de Economía Aplicada, Vol. 24(1), pp. 165-180.

Declaración Universal de los Derechos Humanos (1948), adoptada y proclamada por la Resolución de la Asamblea General de las Naciones Unidas 217 A (iii): del 10 de diciembre de 1948, 4 p.

DÍAZ, I. (2003). "Instituciones y Seguridad Alimentaria. Análisis histórico". En Briz, J. (Coord). Internet, trazabilidad y seguridad alimentaria (pp. 179-209). Madrid: Ed MundiPrensa.

DRIOUCHI, A.; ZOUAG, N. y BOBOC, C. (2009). "Interdependencies of Health, Education and Poverty: The Case of South Mediterranean Economies". Estudios de Economía Aplicada, Vol. 27(2), pp. 523-544.

DURÁN, E. (2011). "Alimentos y bebidas: El precio condiciona la innovación". Revista Alimarket, 247, pp. 71-94.

ENGINDENIZ, S. (2007). "Economic analysis of precessing tomato growing: the case study of Torbali, west Turkey". Spanish journal of agricultural research, 1, pp. 7-15.

ESLAVA, F.; ANDUEZA, F.; ERBURU, J.A.; NAZÁBAL, M. y LEYÚN, M. (2007). "Vacuno de carne: gestión técnico-económica". Navarra agraria, 165, pp. 33-39.

FAO (Organización de las Naciones Unidas para la Alimentación y la Agricultura) (2016): http://www.fao.org/faostat/es/\#home [último acceso: Diciembre de 2016].

FERNÁNDEZ, R. (2002). "Trazabilidad alimentaria: Una herramienta decisiva para la seguridad y la protección de los consumidores". Distribución y Consumo, 62, pp. 5-9. 
FONTELA, E. y GUZMÁN. J. (2003). "Círculos viciosos y virtuosos del desarrollo económico". Estudios de Economía Aplicada, Vol. 21(2), pp. 221-242.

GARCÍA, M.D. (2008). Manual de Marketing. Madrid: ESIC Editorial.

GILBERT, C.L. (2010). "How to understand high food prices". Journal of Agricultural Economics, 61(2), pp. 398-425.

GRACIA, A. y ALBISU, L.M. (1996). "Medición de la calidad y de los efectos de los precios en la demanda de alimentos". Estudios de Economía Aplicada, 6, pp. 131-148.

HANDBURY, J. y WEINSTEIN, D. (2015). "Goods prices and availability in cities". Review of economic studies, 82(1), pp. 258-296.

HEADEY, D. y FAN, S. (2008). "Anatomy of a crisis: the causes and consequences of surging food prices". Agricultural economics, 39(s1), pp. 375-391.

HERRERO, J.M. (2007). "Márgenes en los precios orígen-destino". Agromar Andalucía: Revista de Información de la Consejería de Agricultura y Pesca de Andalucía, 38, pp. 19-21.

JEREZ, M.P.; GONZÁLEZ, A.; HERRERA, J.G.; VÁSQUEZ, M.A.; SEGURA, J. y VILLEGAS, Y. (2009). "Mercadeo de Huevos de Gallinas Criollas (Gallus Gallus L.) en los Valles Centrales de Oaxaca, México". Etnobiología, Vol. 7, №. 1, pp. 86-93.

JÓDAR, S. (2011). "La volatilidad del precio de los alimentos, ¿un problema también al alza?". Informe Mensual - La Caixa, 350, pp. 60-62.

JORDÁ, V; TRUEBA, C. y SARABIA J.M. (2014). "Análisis multidimensional de la desigualdad en el marco del desarrollo humano". Estudios de Economía Aplicada, Vol. 32(2), pp. 765-788.

KÉFI, R. (2008). "Ante la conmoción alimentaria, se impone la toma de decisiones". Economía exterior: Estudios de la revista Política Exterior sobre la internacionalización de la economía española, 45, pp. 91-100.

LANGREO, A. (2004). "Consecuencias de la seguridad alimentaria en el sistema alimentario y la sociedad". Cuadernos La tierra del agricultor y ganadero, 1, pp. 12-23.

LARRUBIA, R. (1996). "Resultados económicos de las producciones agrarias: Evolución de los precios, costos de producción y márgenes de comercialización". Baética: Estudios de arte, geografía e historia, 18, pp. 129-178.

MARTÍNEZ, V. y GARCÍA, J.M. (2010). "El problema de la inestabilidad de los precios de los alimentos. Importancia y soluciones". Boletín económico de ICE, Información Comercial Española, 3001, pp. 23-32.

MARTUSCELLI, A. (2008). "Causas, efectos y opciones en la crisis de los alimentos". Política exterior, 22, 125, pp. 79-95.

MCCALLA, A.F. (1997). "Perspectivas de la seguridad alimentaria en el siglo XXI". Revista española de economía agraria, 181, pp. 31-48.

MOLINA, L.E. (2002). "Reflexiones sobre la seguridad alimentaria y la situación alimentaria internacional". Revista agroalimentaria, 15, pp. 89-99.

MORALES, A. y RENDÓN, A. (2008). "Relaciones entre producción y precios de alimentos con la subnutrición en América Latina". Política y cultura, 30, pp. 235-254.

PÉREZ, M. y MATEA, M.L. (2005). "La evolución de los precios de los alimentos ¿existen diferencias por tipo de establecimiento?". Boletín económico - Banco de España, 12, pp. 43-52.

PÉREZ DE ARMIÑO, K. (2009). "La crisis alimentaria. Más allá de la ayuda". Temas para el debate, 181, pp. 44-46. 
REBOLLAR, S.; HERNÁNDEZ, J.; GARCÍA, J.A.; GARCÍA, R.; TORRES, G.; BÓRQUEZ, J.L. y MEJÍA, P. (2007). "Canales y márgenes de comercialización de caprinos en Tejupilco y Amatepec, estado de México". Agrociencia, Vol. 41, №. 3, pp. 363-370.

REBOLLAR, S.; HERNÁNDEZ, J.; GONZÁLEZ, F.J.; GARCÍA, A.; ALBARRÁN, B. y ROJO, R. (2011). "Canales y márgenes de comercialización del queso añejo en Zacazonapan, México". Archivos de zootecnia, Vol. 60, № 232, pp. 883-889.

SÁNCHEZ, J. y RODRÍGUEZ, Y. (2013). "The importance of food safety to a panorama of volatility in international food prices, the case of México". Ecorfan Journal, 4, 11, pp. 1180-1193.

SANTESMASES, M. (2005). Dyane Versión 3. Diseño y análisis de encuestas en investigación social y de mercados. Madrid: Pirámide.

SIERRA, A.C.; RIVERA, J.A.; ORTIZ, B.; MAGAÑA, M.A.; SIERRA, L.D. y SANGINÉS, J.R. (2005). "Estructura del mercado y comportamiento del precio de la carne de cerdo en Yucatán 1990-2003". Técnica Pecuaria en México, Vol. 43, №. 3, pp. 347-360.

SOTO, F. y RAPALLO, R. (2012). "Alza y volatilidad en los precios de los alimentos oportunidades y desafíos para la seguridad alimentaria y nutricional en Centroamérica". Revista española de desarrollo y cooperación, 30, pp. 153-168.

SUMPSI, J.M. (2013). "The volatility of the agricultural markets and the world food crisis". Cuadernos de estrategia, 161(1), pp. 142-169.

TREJOS, R.A. (2008). "Crisis en los precios de alimentos, pobreza y seguridad alimentaria". Revista IIDH, 48, pp. 269-289.

TUGORES, J. (2014). "Desequilibrios externos globales y cooperación internacional: ¿Dónde estamos?”. Estudios de Economía Aplicada, Vol. 32(3), pp. 911-934. 


\section{Anexo}

\section{Tabla 8}

Variación del diferencial de precios alimentarios entre consumidores y productores

\begin{tabular}{|c|c|c|c|c|c|}
\hline País & $\begin{array}{c}\text { Índice precios } \\
\text { consumidores } \\
2000^{*}\end{array}$ & $\begin{array}{c}\text { Índice precios } \\
\text { consumidores } \\
2010^{*}\end{array}$ & $\begin{array}{c}\text { Índice precios } \\
\text { productores } \\
2000^{*}\end{array}$ & $\begin{array}{c}\text { Índice precios } \\
\text { productores } \\
2010^{*}\end{array}$ & $\begin{array}{c}\% \text { Var diferencial } \\
\text { consumidores I } \\
\text { productores }\end{array}$ \\
\hline Albania & 100,00 & 136,66 & 96,80 & 117,17 & $12,90 \%$ \\
\hline Alemania & 100,00 & 118,46 & 95,24 & 114,18 & $-1,19 \%$ \\
\hline Argelia & 100,00 & 157,14 & 93,69 & 144,59 & $1,82 \%$ \\
\hline Armenia & 100,00 & 169,66 & 74,35 & 143,66 & $-12,19 \%$ \\
\hline Australia & 100,00 & 145,81 & 81,05 & 110,76 & $6,70 \%$ \\
\hline Austria & 100,00 & 125,41 & 97,18 & 119,94 & $1,61 \%$ \\
\hline Bangladesh & 100,00 & 195,90 & 79,73 & 155,87 & $0,21 \%$ \\
\hline Barbados & 100,00 & 178,59 & 92,23 & 116,11 & $41,86 \%$ \\
\hline Bélgica & 100,00 & 129,38 & 94,04 & 104,19 & $16,78 \%$ \\
\hline Botswana & 100,00 & 246,07 & 63,30 & 191,47 & $-18,65 \%$ \\
\hline Brasil & 100,00 & 204,63 & 64,28 & 138,84 & $-5,26 \%$ \\
\hline Bulgaria & 100,00 & 161,72 & 89,39 & 135,19 & $6,93 \%$ \\
\hline Cabo Verde & 100,00 & 122,63 & 97,81 & 97,58 & $22,92 \%$ \\
\hline Camerún & 100,00 & 139,38 & 79,38 & 143,66 & $-22,98 \%$ \\
\hline Canadá & 100,00 & 131,95 & 90,94 & 128,39 & $-6,54 \%$ \\
\hline Chipre & 100,00 & 149,51 & 87,24 & 125,46 & $3,96 \%$ \\
\hline Colombia & 100,00 & 191,69 & 78,28 & 136,45 & $9,97 \%$ \\
\hline Croacia & 100,00 & 128,65 & 89,82 & 114,52 & $0,90 \%$ \\
\hline Dinamarca & 100,00 & 124,17 & 105,20 & 108,23 & $20,69 \%$ \\
\hline Ecuador & 100,00 & 141,51 & 65,78 & 153,03 & $-39,17 \%$ \\
\hline Egipto & 100,00 & 225,31 & 66,22 & 161,87 & $-7,83 \%$ \\
\hline El Salvador & 100,00 & 100,00 & 84,28 & 145,52 & $-42,08 \%$ \\
\hline Eslovaquia & 100,00 & 128,06 & 94,51 & 96,47 & $25,46 \%$ \\
\hline Eslovenia & 100,00 & 153,10 & 88,00 & 114,65 & $17,51 \%$ \\
\hline España & 100,00 & 130,89 & 96,56 & 107,62 & $17,44 \%$ \\
\hline Estados Unidos & 100,00 & 130,89 & 81,58 & 147,93 & $-27,82 \%$ \\
\hline Estonia & 100,00 & 153,38 & 75,77 & 120,62 & $-3,65 \%$ \\
\hline Etiopía & 100,00 & 359,67 & 85,65 & 215,08 & $43,23 \%$ \\
\hline Fiji & 100,00 & 161,83 & 83,38 & 116,81 & $15,52 \%$ \\
\hline Filipinas & 100,00 & 166,07 & 77,59 & 141,01 & $-8,62 \%$ \\
\hline Finlandia & 100,00 & 120,67 & 99,89 & 110,97 & $8,62 \%$ \\
\hline Francia & 100,00 & 121,37 & 103,08 & 126,70 & $-1,26 \%$ \\
\hline Ghana & 100,00 & 424,94 & 37,02 & 226,56 & $-30,56 \%$ \\
\hline Grecia & 100,00 & 135,10 & 83,19 & 118,06 & $-4,80 \%$ \\
\hline Honduras & 100,00 & 198,62 & 71,46 & 142,87 & $-0,66 \%$ \\
\hline Hungría & 100,00 & 191,67 & 94,90 & 139,73 & $30,18 \%$ \\
\hline Indonesia & 100,00 & 246,98 & 58,71 & 185,65 & $-21,89 \%$ \\
\hline Irán & 100,00 & 164,80 & 54,28 & 204,01 & $-56,15 \%$ \\
\hline Islas Mauricio & 100,00 & 205,85 & 71,85 & 646,17 & $-77,11 \%$ \\
\hline Israel & 100,00 & 138,62 & 78,19 & 144,43 & $-24,96 \%$ \\
\hline Japón & 100,00 & 101,03 & 98,63 & 101,26 & $-1,59 \%$ \\
\hline Jordania & 100,00 & 167,67 & 86,89 & 152,29 & $-4,33 \%$ \\
\hline Laos & 100,00 & 231,21 & 64,50 & 176,91 & $-15,70 \%$ \\
\hline Letonia & 100,00 & 188,72 & 74,46 & 133,15 & $5,54 \%$ \\
\hline Lituania & 100,00 & 145,79 & 87,31 & 145,20 & $-12,34 \%$ \\
\hline Madagascar & 100,00 & 257,21 & 75,83 & 170,71 & $14,25 \%$ \\
\hline Malawi & 100,00 & 271,20 & 30,53 & 207,71 & $-60,14 \%$ \\
\hline
\end{tabular}


Tabla 8 (Continuación)

Variación del diferencial de precios alimentarios entre consumidores y productores

\begin{tabular}{|c|c|c|c|c|c|}
\hline País & $\begin{array}{c}\text { Índice precios } \\
\text { consumidores } \\
2000^{*}\end{array}$ & $\begin{array}{c}\text { Índice precios } \\
\text { consumidores } \\
2010^{*}\end{array}$ & $\begin{array}{c}\text { Índice precios } \\
\text { productores } \\
2000^{*}\end{array}$ & $\begin{array}{c}\text { Índice precios } \\
\text { productores } \\
2010^{*}\end{array}$ & $\begin{array}{c}\text { \% Var diferencial } \\
\text { consumidores I } \\
\text { productores }\end{array}$ \\
\hline Malta & 100,00 & 138,34 & 104,80 & 113,37 & $27,88 \%$ \\
\hline México & 100,00 & 174,01 & 80,67 & 136,42 & $2,90 \%$ \\
\hline Moldavia & 100,00 & 140,13 & 69,05 & 154,13 & $-37,22 \%$ \\
\hline Namibia & 100,00 & 179,03 & 74,43 & 216,84 & $-38,55 \%$ \\
\hline Nepal & 100,00 & 211,28 & 81,97 & 163,58 & $5,87 \%$ \\
\hline Nicaragua & 100,00 & 263,77 & 67,37 & 163,82 & $8,47 \%$ \\
\hline Nigeria & 100,00 & 355,81 & 50,45 & 179,04 & $0,26 \%$ \\
\hline Noruega & 100,00 & 116,81 & 93,68 & 123,12 & $-11,12 \%$ \\
\hline Países Bajos & 100,00 & 101,78 & 102,57 & 108,41 & $-3,70 \%$ \\
\hline Pakistán & 100,00 & 267,97 & 81,85 & 175,01 & $25,33 \%$ \\
\hline Panamá & 100,00 & 142,80 & 100,51 & 123,97 & $15,78 \%$ \\
\hline Portugal & 100,00 & 116,66 & 93,89 & 109,87 & $-0,31 \%$ \\
\hline Reino Unido & 100,00 & 135,97 & 89,80 & 142,04 & $-14,04 \%$ \\
\hline Rep. Checa & 100,00 & 115,70 & 99,77 & 93,02 & $24,10 \%$ \\
\hline Rep. Corea & 100,00 & 123,82 & 85,44 & 114,16 & $-7,33 \%$ \\
\hline Rep. Dominicana & 100,00 & 320,41 & 48,76 & 143,01 & $9,25 \%$ \\
\hline Rumanía & 100,00 & 266,18 & 47,15 & 146,87 & $-14,55 \%$ \\
\hline Rusia & 100,00 & 327,85 & 58,87 & 168,88 & $14,29 \%$ \\
\hline Sudáfrica & 100,00 & 111,03 & 67,77 & 157,08 & $-52,10 \%$ \\
\hline Suecia & 100,00 & 120,87 & 102,24 & 126,85 & $-2,58 \%$ \\
\hline Suiza & 100,00 & 107,88 & 101,84 & 92,89 & $18,27 \%$ \\
\hline Tailandia & 100,00 & 153,39 & 62,65 & 136,47 & $-29,58 \%$ \\
\hline Túnez & 100,00 & 147,22 & 82,22 & 130,61 & $-7,32 \%$ \\
\hline Turquía & 100,00 & 186,20 & 30,22 & 153,47 & $-63,34 \%$ \\
\hline Ucrania & 100,00 & 122,70 & 67,37 & 259,19 & $-68,11 \%$ \\
\hline Yemen & 100,00 & 110,43 & 62,31 & 186,79 & $-63,16 \%$ \\
\hline
\end{tabular}

*Base 2000.

*Base 2004-2006.

Fuente: Elaboración propia según datos de FAO (2016).

Tabla 9A

Indicadores de seguridad alimentaria utilizados (\%)

\begin{tabular}{|c|c|c|c|c|c|c|c|c|c|c|c|c|c|c|}
\hline \multirow{3}{*}{$\begin{array}{c}\text { Unidades } \\
\text { Países } \\
\end{array}$} & \multirow{2}{*}{\multicolumn{2}{|c|}{$\begin{array}{c}\begin{array}{c}\text { Suficiencia de } \\
\text { suministro } \\
\text { medio de } \\
\text { energía } \\
\text { alimentaria* }\end{array} \\
\%\end{array}$}} & \multirow{2}{*}{\multicolumn{2}{|c|}{\begin{tabular}{|c} 
Valor medio de \\
la producción \\
alimentaria*
\end{tabular}}} & \multirow{2}{*}{\multicolumn{2}{|c|}{\begin{tabular}{|c|}
$\begin{array}{c}\% \text { Suministro de } \\
\text { energía } \\
\text { alimentaria de } \\
\text { cereales, raíces y } \\
\text { tubérculos* }\end{array}$ \\
$\%$ \\
\end{tabular}}} & \multirow{2}{*}{\multicolumn{2}{|c|}{\begin{tabular}{|c|}
$\begin{array}{c}\text { Suministro medio } \\
\text { de proteínas* }\end{array}$ \\
Gr. persona y día
\end{tabular}}} & \multirow{2}{*}{\multicolumn{2}{|c|}{\begin{tabular}{|c|}
$\begin{array}{c}\text { Suministro } \\
\text { medio de } \\
\text { proteínas de } \\
\text { origen animal* }\end{array}$ \\
Gr. persona y día \\
\end{tabular}}} & \multirow{2}{*}{\multicolumn{2}{|c|}{$\begin{array}{c}\text { PIB per cápita } \\
\text { (en poder } \\
\text { adquisitivo } \\
\text { equivalente) }\end{array}$}} & \multicolumn{2}{|c|}{$\begin{array}{c}\text { \% Dependencia } \\
\text { de } \\
\text { importaciones } \\
\text { de cereales* }\end{array}$} \\
\hline & & & & & & & & & & & & & & \\
\hline & 2000 & 2010 & 2000 & 2010 & 2000 & 2010 & 2000 & 2010 & 2000 & 2010 & 2000 & 2010 & 2000 & 2010 \\
\hline Albania & 117 & 121 & 241 & 349 & 51 & 41 & 92 & 101 & 40 & 51 & 5403 & 9727 & 46 & 41 \\
\hline Alemania & 131 & 138 & 376 & 391 & 28 & 28 & 95 & 103 & 57 & 62 & 35864 & 39669 & 13 & 26 \\
\hline Argelia & 124 & 135 & 119 & 178 & 60 & 57 & 77 & 88 & 19 & 24 & 9886 & 12494 & 80 & 68 \\
\hline Armenia & 95 & 115 & 172 & 316 & 62 & 43 & 66 & 85 & 20 & 39 & 2919 & 6508 & 57 & 56 \\
\hline Australia & 122 & 130 & 1170 & 990 & 25 & 25 & 100 & 104 & 67 & 69 & 35248 & 41328 & 1 & 3 \\
\hline Austria & 150 & 149 & 520 & 505 & 27 & 26 & 112 & 106 & 70 & 64 & 37721 & 41787 & 16 & 33 \\
\hline Bangladesh & 104 & 107 & 105 & 135 & 84 & 80 & 49 & 55 & 7 & 10 & 1384 & 2135 & 12 & 11 \\
\hline Barbados & 117 & 123 & 184 & 165 & 33 & 32 & 84 & 91 & 48 & 52 & 14714 & 15335 & 110 & 111 \\
\hline Bélgica & 149 & 148 & 535 & 460 & 26 & 30 & 102 & 102 & 64 & 60 & 36741 & 39610 & 121 & 123 \\
\hline Botswana & 92 & 96 & 114 & 145 & 51 & 49 & 66 & 64 & 25 & 25 & 10226 & 13286 & 98 & 91 \\
\hline
\end{tabular}


Tabla 9A (Continuación)

Indicadores de seguridad alimentaria utilizados (\%)

\begin{tabular}{|c|c|c|c|c|c|c|c|c|c|c|c|c|c|c|}
\hline \multirow{3}{*}{$\begin{array}{c}\text { Unidades } \\
\text { Brasil } \\
\end{array}$} & \multicolumn{2}{|c|}{$\begin{array}{l}\text { Suficiencia de } \\
\text { suministro } \\
\text { medio de } \\
\text { energía } \\
\text { alimentaria* }\end{array}$} & \multicolumn{2}{|c|}{$\begin{array}{c}\text { Valor medio de } \\
\text { la producción } \\
\text { alimentaria** }\end{array}$} & \multicolumn{2}{|c|}{$\begin{array}{c}\text { \% Suministro de } \\
\text { energía } \\
\text { alimentaria de } \\
\text { cereales, raíces y } \\
\text { tubérculos* }\end{array}$} & \multicolumn{2}{|c|}{$\begin{array}{c}\text { Suministro medio } \\
\text { de proteínas* }\end{array}$} & \multicolumn{2}{|c|}{$\begin{array}{c}\text { Suministro } \\
\text { medio de } \\
\text { proteínas de } \\
\text { origen animal* }\end{array}$} & \multicolumn{2}{|c|}{$\begin{array}{l}\text { PIB per cápita } \\
\text { (en poder } \\
\text { adquisitivo } \\
\text { equivalente) }\end{array}$} & \multicolumn{2}{|c|}{$\begin{array}{c}\% \text { Dependencia } \\
\text { de } \\
\text { importaciones } \\
\text { de cereales* }\end{array}$} \\
\hline & \multicolumn{2}{|c|}{$\%$} & \multicolumn{2}{|c|}{$\begin{array}{l}\text { \$ Internacs. } \\
\text { per cápita }\end{array}$} & \multicolumn{2}{|c|}{$\%$} & \multicolumn{2}{|c|}{ Gr. persona y día } & \multicolumn{2}{|c|}{ Gr. persona y día } & \multicolumn{2}{|c|}{$\begin{array}{l}\text { (\$ Internacs. en } \\
\text { valores 2011) }\end{array}$} & \multicolumn{2}{|c|}{$\%$} \\
\hline & 122 & 133 & 456 & 649 & 35 & 34 & 79 & 92 & 41 & 49 & 11015 & 14043 & 19 & 14 \\
\hline Bulgaria & 113 & 113 & 370 & 370 & 42 & 43 & 86 & 82 & 41 & 39 & 9192 & 15150 & 3 & 7 \\
\hline Cabo Verde & 105 & 113 & 77 & 98 & 50 & 46 & 62 & 75 & 25 & 34 & 3772 & 6005 & 73 & 94 \\
\hline Camerún & 97 & 114 & 160 & 226 & 57 & 54 & 55 & 68 & 12 & 13 & 2298 & 2465 & 30 & 26 \\
\hline Canadá & 140 & 135 & 690 & 740 & 28 & 28 & 107 & 104 & 60 & 57 & 37259 & 40713 & 11 & 12 \\
\hline Chipre & 107 & 104 & 449 & 301 & 28 & 28 & 86 & 79 & 52 & 48 & 28784 & 31907 & 87 & 91 \\
\hline Colombia & 116 & 110 & 252 & 268 & 40 & 38 & 64 & 62 & 30 & 32 & 8414 & 10777 & 54 & 64 \\
\hline Croacia & 105 & 123 & 255 & 278 & 39 & 32 & 69 & 83 & 31 & 46 & 15389 & 19627 & 8 & 8 \\
\hline Dinamarca & 131 & 133 & 1070 & 1087 & 29 & 29 & 104 & 107 & 65 & 67 & 40703 & 41558 & 13 & 16 \\
\hline Ecuador & 104 & 110 & 380 & 442 & 39 & 34 & 57 & 66 & 29 & 41 & 7251 & 9019 & 37 & 38 \\
\hline Egipto & 148 & 151 & 230 & 264 & 66 & 65 & 94 & 102 & 18 & 24 & 7811 & 10621 & 36 & 46 \\
\hline El Salvador & 116 & 113 & 133 & 151 & 52 & 49 & 64 & 70 & 19 & 24 & 6266 & 7237 & 47 & 54 \\
\hline Eslovaquia & 111 & 114 & 283 & 264 & 38 & 35 & 73 & 74 & 35 & 36 & 15341 & 24428 & 11 & 21 \\
\hline Eslovenia & 121 & 127 & 357 & 332 & 39 & 38 & 102 & 100 & 60 & 58 & 22106 & 28018 & 60 & 63 \\
\hline España & 133 & 127 & 713 & 664 & 26 & 25 & 112 & 105 & 72 & 66 & 30072 & 31829 & 29 & 41 \\
\hline USA & 146 & 143 & 632 & 663 & 25 & 25 & 114 & 110 & 73 & 71 & 45956 & 49307 & 3 & 3 \\
\hline Estonia & 122 & 128 & 257 & 367 & 36 & 37 & 89 & 96 & 52 & 52 & 14319 & 21212 & 31 & 25 \\
\hline Etiopía & 83 & 96 & 75 & 106 & 82 & 76 & 51 & 61 & 5 & 8 & 612 & 1062 & 11 & 11 \\
\hline Fiji & 124 & 123 & 277 & 231 & 48 & 48 & 73 & 74 & 30 & 31 & 6870 & 7366 & 101 & 142 \\
\hline Filipinas & 110 & 118 & 184 & 208 & 57 & 60 & 54 & 61 & 22 & 25 & 4243 & 5614 & 24 & 22 \\
\hline Finlandia & 124 & 128 & 359 & 350 & 32 & 32 & 102 & 112 & 63 & 69 & 32926 & 37732 & 12 & 9 \\
\hline Francia & 145 & 142 & 669 & 607 & 28 & 29 & 118 & 113 & 78 & 72 & 34127 & 35718 & 9 & 10 \\
\hline Ghana & 113 & 134 & 222 & 266 & 69 & 66 & 51 & 60 & 16 & 16 & 2240 & 3065 & 24 & 26 \\
\hline Grecia & 143 & 138 & 711 & 595 & 32 & 30 & 117 & 112 & 64 & 63 & 24247 & 29036 & 26 & 32 \\
\hline Honduras & 114 & 118 & 166 & 210 & 48 & 47 & 60 & 65 & 22 & 25 & 3483 & 4270 & 46 & 59 \\
\hline Hungría & 122 & 120 & 536 & 503 & 29 & 30 & 88 & 82 & 51 & 45 & 17737 & 21998 & 2 & 6 \\
\hline Indonesia & 108 & 117 & 164 & 223 & 72 & 70 & 53 & 60 & 12 & 17 & 5552 & 8027 & 14 & 13 \\
\hline Irán & 130 & 126 & 275 & 326 & 60 & 53 & 83 & 86 & 19 & 24 & 10694 & 15705 & 41 & 30 \\
\hline Islas Mauricio & 123 & 129 & 202 & 207 & 47 & 49 & 78 & 90 & 33 & 39 & 11356 & 15233 & 113 & 112 \\
\hline Israel & 154 & 155 & 362 & 367 & 33 & 35 & 119 & 126 & 65 & 70 & 25476 & 29378 & 95 & 95 \\
\hline Japón & 119 & 111 & 143 & 138 & 41 & 41 & 96 & 88 & 55 & 49 & 32186 & 34571 & 81 & 81 \\
\hline Jordania & 123 & 138 & 147 & 189 & 50 & 48 & 72 & 82 & 23 & 29 & 7695 & 11256 & 98 & 99 \\
\hline Laos & 94 & 102 & 175 & 232 & 78 & 72 & 55 & 63 & 10 & 13 & 2327 & 3901 & 2 & 2 \\
\hline Letonia & 115 & 132 & 219 & 350 & 41 & 33 & 79 & 97 & 40 & 58 & 11520 & 18625 & 10 & 59 \\
\hline Lituania & 129 & 138 & 340 & 516 & 49 & 39 & 103 & 124 & 50 & 75 & 11936 & 20672 & 7 & 15 \\
\hline Madagascar & 96 & 98 & 155 & 155 & 77 & 79 & 46 & 48 & 12 & 11 & 1456 & 1391 & 12 & 9 \\
\hline Malawi & 105 & 111 & 137 & 165 & 75 & 71 & 56 & 62 & 4 & 6 & 745 & 737 & 4 & 6 \\
\hline Malta & 133 & 133 & 208 & 179 & 37 & 35 & 109 & 109 & 58 & 59 & 26117 & 27941 & 95 & 92 \\
\hline México & 132 & 129 & 263 & 277 & 47 & 44 & 86 & 86 & 37 & 41 & 14704 & 15460 & 35 & 35 \\
\hline Moldavia & 103 & 113 & 293 & 372 & 61 & 46 & 68 & 72 & 24 & 33 & 2320 & 3911 & 2 & 7 \\
\hline Namibia & 99 & 90 & 201 & 186 & 59 & 55 & 66 & 59 & 27 & 23 & 6155 & 8394 & 70 & 56 \\
\hline Nepal & 108 & 119 & 159 & 186 & 74 & 69 & 58 & 65 & 9 & 11 & 1577 & 1999 & 2 & 4 \\
\hline Nicaragua & 100 & 113 & 171 & 240 & 51 & 51 & 54 & 65 & 15 & 20 & 3436 & 3983 & 30 & 36 \\
\hline Nigeria & 121 & 127 & 206 & 195 & 65 & 65 & 59 & 63 & 8 & 10 & 2855 & 5148 & 14 & 22 \\
\hline Noruega & 135 & 137 & 280 & 257 & 32 & 31 & 105 & 109 & 65 & 65 & 58173 & 61875 & 31 & 41 \\
\hline Países Bajos & 127 & 124 & 754 & 792 & 21 & 27 & 107 & 108 & 75 & 73 & 39222 & 42944 & 109 & 107 \\
\hline Pakistán & 109 & 108 & 173 & 192 & 52 & 50 & 61 & 64 & 22 & 26 & 3366 & 4220 & 6 & 4 \\
\hline
\end{tabular}


Tabla 9A (Continuación)

Indicadores de seguridad alimentaria utilizados (\%)

\begin{tabular}{|c|c|c|c|c|c|c|c|c|c|c|c|c|c|c|}
\hline \multirow{3}{*}{$\begin{array}{c}\text { Unidades } \\
\text { Panamá }\end{array}$} & \multicolumn{2}{|c|}{$\begin{array}{l}\text { Suficiencia de } \\
\text { suministro } \\
\text { medio de } \\
\text { energía } \\
\text { alimentaria* }\end{array}$} & \multicolumn{2}{|c|}{$\begin{array}{l}\text { Valor medio de } \\
\text { la producción } \\
\text { alimentaria** }\end{array}$} & \multicolumn{2}{|c|}{$\begin{array}{c}\text { \% Suministro de } \\
\text { energía } \\
\text { alimentaria de } \\
\text { cereales, raíces y } \\
\text { tubérculos* }\end{array}$} & \multicolumn{2}{|c|}{$\begin{array}{c}\text { Suministro medio } \\
\text { de proteínas* }\end{array}$} & \multicolumn{2}{|c|}{$\begin{array}{c}\text { Suministro } \\
\text { medio de } \\
\text { proteínas de } \\
\text { origen animal* }\end{array}$} & \multicolumn{2}{|c|}{$\begin{array}{l}\text { PIB per cápita } \\
\text { (en poder } \\
\text { adquisitivo } \\
\text { equivalente) }\end{array}$} & \multicolumn{2}{|c|}{$\begin{array}{c}\% \text { Dependencia } \\
\text { de } \\
\text { importaciones } \\
\text { de cereales* }\end{array}$} \\
\hline & \multicolumn{2}{|c|}{$\%$} & \multicolumn{2}{|c|}{$\begin{array}{l}\text { \$ Internacs. } \\
\text { per cápita }\end{array}$} & \multicolumn{2}{|c|}{$\%$} & \multicolumn{2}{|c|}{ Gr. persona y día } & \multicolumn{2}{|c|}{ Gr. persona y día } & \multicolumn{2}{|c|}{$\begin{array}{l}\text { (\$ Internacs. en } \\
\text { valores 2011) }\end{array}$} & \multicolumn{2}{|c|}{$\%$} \\
\hline & 98 & 113 & 259 & 240 & 40 & 45 & 63 & 75 & 36 & 40 & 9954 & 14921 & 64 & 72 \\
\hline Portugal & 141 & 140 & 395 & 395 & 32 & 32 & 114 & 114 & 68 & 70 & 25057 & 26116 & 71 & 84 \\
\hline Reino Unido & 136 & 137 & 271 & 257 & 31 & 32 & 100 & 102 & 55 & 58 & 31419 & 34686 & 20 & 21 \\
\hline Rep. Checa & 122 & 129 & 372 & 340 & 31 & 31 & 91 & 92 & 55 & 54 & 19491 & 26619 & 5 & 11 \\
\hline Rep. Corea & 128 & 133 & 221 & 211 & 49 & 44 & 88 & 93 & 36 & 44 & 20757 & 30440 & 72 & 75 \\
\hline Rep. Dominic. & 96 & 107 & 209 & 269 & 32 & 32 & 47 & 58 & 22 & 28 & 7187 & 10412 & 76 & 75 \\
\hline Rumanía & 127 & 135 & 338 & 388 & 49 & 45 & 97 & 106 & 42 & 51 & 9828 & 16647 & 4 & 12 \\
\hline Rusia & 116 & 133 & 219 & 284 & 47 & 41 & 86 & 101 & 42 & 54 & 13173 & 21734 & 8 & 2 \\
\hline Sudáfrica & 121 & 125 & 210 & 237 & 57 & 53 & 75 & 82 & 25 & 34 & 9519 & 11651 & 13 & 18 \\
\hline Suecia & 122 & 124 & 319 & 287 & 28 & 28 & 103 & 108 & 68 & 71 & 34915 & 40880 & 11 & 16 \\
\hline Suiza & 133 & 135 & 339 & 331 & 26 & 24 & 95 & 94 & 58 & 59 & 46809 & 50963 & 41 & 56 \\
\hline Tailandia & 107 & 113 & 326 & 390 & 52 & 50 & 58 & 59 & 23 & 23 & 8939 & 12822 & 8 & 12 \\
\hline Túnez & 142 & 141 & 295 & 323 & 53 & 53 & 90 & 97 & 24 & 26 & 7409 & 10380 & 67 & 60 \\
\hline Turquía & 157 & 154 & 413 & 456 & 54 & 47 & 105 & 103 & 26 & 31 & 13090 & 16758 & 8 & 13 \\
\hline Ucrania & 116 & 125 & 293 & 418 & 50 & 42 & 81 & 86 & 34 & 41 & 4817 & 7857 & 2 & 1 \\
\hline Yemen & 101 & 101 & 60 & 75 & 67 & 63 & 57 & 58 & 10 & 13 & 4018 & 4534 & 79 & 83 \\
\hline
\end{tabular}

*Media móvil nivel 3.

Fuente: Elaboración propia según datos de FAO (2016).

Tabla 9B

Indicadores de seguridad alimentaria utilizados (\%). (Cont)

\begin{tabular}{|c|c|c|c|c|c|c|c|c|c|c|c|c|c|c|}
\hline \multirow{3}{*}{$\begin{array}{c}\text { Unidades } \\
\text { Países }\end{array}$} & \multicolumn{2}{|c|}{$\begin{array}{l}\% \text { Tierra de } \\
\text { cultivo } \\
\text { equipada con } \\
\text { sistemas de } \\
\text { riego* }\end{array}$} & \multicolumn{2}{|c|}{$\begin{array}{c}\% \\
\text { Importaciones } \\
\text { de alimentos } \\
\text { sobre } \\
\text { exportaciones } \\
\text { totales* }\end{array}$} & \multicolumn{2}{|c|}{$\begin{array}{l}\text { Variabilidad del } \\
\text { suministro de } \\
\text { alimentos per } \\
\text { cápita }\end{array}$} & \multicolumn{2}{|c|}{$\begin{array}{c}\text { \% Población con } \\
\text { acceso a fuentes } \\
\text { mejoradas de } \\
\text { agua }\end{array}$} & \multicolumn{2}{|c|}{$\begin{array}{l}\text { \% Población con } \\
\text { acceso a } \\
\text { instalaciones de } \\
\text { saneamiento }\end{array}$} & \multicolumn{2}{|c|}{$\begin{array}{c}\text { Frecuencia de } \\
\text { anemia entre } \\
\text { mujeres } \\
\text { embarazadas }\end{array}$} & \multicolumn{2}{|c|}{$\begin{array}{l}\text { Frecuencia de } \\
\text { anemia entre } \\
\text { niños de menos } \\
\text { de } 5 \text { años de } \\
\text { edad }\end{array}$} \\
\hline & \multicolumn{2}{|c|}{$\%$} & \multicolumn{2}{|c|}{$\%$} & \multicolumn{2}{|c|}{$\begin{array}{c}\text { Kilocalorías por } \\
\text { persona y día }\end{array}$} & \multicolumn{2}{|c|}{$\%$} & \multicolumn{2}{|c|}{$\%$} & \multicolumn{2}{|c|}{$\%$} & \multicolumn{2}{|c|}{$\%$} \\
\hline & 2000 & 2010 & 2000 & 2010 & 2000 & 2010 & 2000 & 2010 & 2000 & 2010 & 2000 & 2010 & 2000 & 2010 \\
\hline Albania & 59 & 54 & 77 & 38 & 55 & 16 & 97 & 96 & 84 & 90 & 28 & 22 & 25 & 22 \\
\hline Alemania & 4 & 5 & 4 & 4 & 49 & 18 & 100 & 100 & 100 & 100 & 24 & 24 & 12 & 13 \\
\hline Argelia & 7 & 8 & 13 & 11 & 34 & 25 & 89 & 84 & 92 & 95 & 36 & 32 & 35 & 32 \\
\hline Armenia & 61 & 61 & 52 & 48 & 82 & 45 & 93 & 99 & 89 & 90 & 22 & 27 & 26 & 33 \\
\hline Australia & 5 & 6 & 3 & 3 & 45 & 23 & 100 & 100 & 100 & 100 & 24 & 24 & 13 & 15 \\
\hline Austria & 7 & 9 & 5 & 6 & 62 & 19 & 100 & 100 & 100 & 100 & 25 & 25 & 12 & 13 \\
\hline Bangladesh & 50 & 67 & 26 & 24 & 58 & 20 & 76 & 83 & 45 & 55 & 52 & 48 & 64 & 56 \\
\hline Barbados & 33 & 42 & 45 & 51 & 71 & 64 & 99 & 100 & 90 & 0 & 36 & 29 & 37 & 37 \\
\hline Bélgica & 4 & 3 & 6 & 6 & 3 & 15 & 100 & 100 & 100 & 100 & 23 & 24 & 11 & 13 \\
\hline Botswana & 1 & 1 & 12 & 11 & 49 & 23 & 95 & 97 & 52 & 64 & 35 & 32 & 41 & 42 \\
\hline Brasil & 6 & 8 & 6 & 3 & 19 & 16 & 94 & 97 & 75 & 80 & 36 & 32 & 23 & 23 \\
\hline Bulgaria & 18 & 3 & 6 & 9 & 105 & 40 & 100 & 100 & 100 & 100 & 29 & 26 & 27 & 27 \\
\hline Cabo Verde & 7 & 7 & 578 & 365 & 17 & 28 & 83 & 88 & 44 & 62 & 50 & 43 & 70 & 61 \\
\hline Camerún & 0 & 1 & 13 & 19 & 16 & 15 & 62 & 72 & 42 & 45 & 56 & 50 & 72 & 64 \\
\hline Canadá & 2 & 2 & 3 & 5 & 80 & 62 & 100 & 100 & 100 & 100 & 22 & 23 & 12 & 14 \\
\hline Chipre & 42 & 53 & 26 & 52 & 35 & 48 & 100 & 100 & 100 & 100 & 31 & 31 & 17 & 18 \\
\hline Colombia & 35 & 61 & 8 & 7 & 22 & 43 & 90 & 91 & 75 & 79 & 43 & 31 & 35 & 29 \\
\hline
\end{tabular}


Tabla 9B (Continuación)

Indicadores de seguridad alimentaria utilizados (\%). (Cont)

\begin{tabular}{|c|c|c|c|c|c|c|c|c|c|c|c|c|c|c|}
\hline & \multicolumn{2}{|c|}{$\begin{array}{c}\% \text { Tierra de } \\
\text { cultivo } \\
\text { equipada con } \\
\text { sistemas de } \\
\text { riego* }\end{array}$} & \multicolumn{2}{|c|}{$\begin{array}{c}\% \\
\text { Importaciones } \\
\text { de alimentos } \\
\text { sobre } \\
\text { exportaciones } \\
\text { totales* }\end{array}$} & \multicolumn{2}{|c|}{$\begin{array}{l}\text { Variabilidad del } \\
\text { suministro de } \\
\text { alimentos per } \\
\text { cápita }\end{array}$} & \multicolumn{2}{|c|}{$\begin{array}{c}\text { \% Población con } \\
\text { acceso a fuentes } \\
\text { mejoradas de } \\
\text { agua }\end{array}$} & \multicolumn{2}{|c|}{$\begin{array}{c}\text { \% Población con } \\
\text { acceso a } \\
\text { instalaciones de } \\
\text { saneamiento }\end{array}$} & \multicolumn{2}{|c|}{$\begin{array}{c}\text { Frecuencia de } \\
\text { anemia entre } \\
\text { mujeres } \\
\text { embarazadas }\end{array}$} & \multicolumn{2}{|c|}{$\begin{array}{c}\text { Frecuencia de } \\
\text { anemia entre } \\
\text { niños de menos } \\
\text { de } 5 \text { años de } \\
\text { edad }\end{array}$} \\
\hline Unidades & \multicolumn{2}{|c|}{$\%$} & \multicolumn{2}{|c|}{$\%$} & \multicolumn{2}{|c|}{$\begin{array}{l}\text { Kilocalorías por } \\
\text { persona y día }\end{array}$} & \multicolumn{2}{|c|}{$\%$} & \multicolumn{2}{|c|}{$\%$} & \multicolumn{2}{|c|}{$\%$} & \multicolumn{2}{|c|}{$\%$} \\
\hline Países & 2000 & 2010 & 2000 & 2010 & 2000 & 2010 & 2000 & 2010 & 2000 & 2010 & 2000 & 2010 & 2000 & 2010 \\
\hline Croacia & 0 & 3 & 11 & 14 & 92 & 22 & 99 & 99 & 98 & 98 & 31 & 27 & 27 & 26 \\
\hline Dinamarca & 20 & 18 & 5 & 7 & 47 & 45 & 100 & 100 & 100 & 100 & 23 & 24 & 12 & 13 \\
\hline Ecuador & 54 & 100 & 6 & 6 & 31 & 19 & 80 & 85 & 70 & 81 & 36 & 30 & 40 & 40 \\
\hline Egipto & 100 & 100 & 46 & 37 & 15 & 34 & 96 & 99 & 86 & 95 & 30 & 30 & 35 & 45 \\
\hline El Salvador & 7 & 7 & 19 & 26 & 25 & 7 & 84 & 90 & 61 & 70 & 36 & 29 & 20 & 29 \\
\hline Eslovaquia & 12 & 8 & 4 & 5 & 37 & 33 & 100 & 100 & 100 & 100 & 28 & 26 & 27 & 27 \\
\hline Eslovenia & 2 & 5 & 5 & 6 & 106 & 51 & 100 & 100 & 100 & 100 & 29 & 25 & 27 & 27 \\
\hline España & 28 & 30 & 6 & 8 & 43 & 23 & 100 & 100 & 100 & 100 & 25 & 25 & 11 & 13 \\
\hline USA & 15 & 17 & 4 & 5 & 16 & 63 & 99 & 99 & 100 & 100 & 13 & 16 & 6 & 6 \\
\hline Estonia & 1 & 1 & 10 & 7 & 76 & 28 & 99 & 99 & 95 & 95 & 28 & 26 & 26 & 25 \\
\hline Etiopía & 3 & 2 & 52 & 55 & 23 & 29 & 29 & 48 & 8 & 21 & 37 & 24 & 64 & 51 \\
\hline Fiji & 2 & 2 & 17 & 30 & 26 & 21 & 91 & 96 & 74 & 87 & 43 & 36 & 31 & 32 \\
\hline Filipinas & 27 & 29 & 5 & 10 & 38 & 21 & 88 & 92 & 66 & 74 & 46 & 34 & 36 & 35 \\
\hline Finlandia & 4 & 3 & 3 & 4 & 69 & 29 & 100 & 100 & 100 & 100 & 23 & 24 & 12 & 13 \\
\hline Francia & 14 & 14 & 5 & 7 & 35 & 36 & 100 & 100 & 100 & 100 & 25 & 25 & 12 & 13 \\
\hline Ghana & 1 & 1 & 17 & 14 & 27 & 27 & 71 & 85 & 10 & 14 & 61 & 62 & 79 & 77 \\
\hline Grecia & 49 & 61 & 22 & 23 & 42 & 55 & 99 & 100 & 98 & 99 & 26 & 27 & 13 & 14 \\
\hline Honduras & 7 & 9 & 29 & 15 & 17 & 19 & 81 & 88 & 63 & 77 & 28 & 22 & 34 & 39 \\
\hline Hungría & 5 & 4 & 2 & 3 & 36 & 42 & 99 & 100 & 100 & 100 & 29 & 26 & 26 & 26 \\
\hline Indonesia & 27 & 29 & 5 & 6 & 32 & 11 & 78 & 84 & 47 & 57 & 40 & 30 & 42 & 33 \\
\hline Irán & 50 & 53 & 10 & 7 & 23 & 26 & 94 & 96 & 79 & 88 & 29 & 26 & 40 & 33 \\
\hline Islas Mauricio & 23 & 26 & 14 & 24 & 44 & 42 & 99 & 100 & 89 & 91 & 38 & 31 & 54 & 44 \\
\hline Israel & 61 & 76 & 5 & 6 & 25 & 60 & 100 & 100 & 100 & 100 & 23 & 24 & 12 & 15 \\
\hline Japón & 59 & 58 & 6 & 5 & 21 & 45 & 100 & 100 & 100 & 100 & 31 & 31 & 13 & 15 \\
\hline Jordania & 40 & 52 & 34 & 29 & 61 & 59 & 97 & 96 & 98 & 98 & 31 & 28 & 32 & 32 \\
\hline Laos & 31 & 22 & 11 & 10 & 20 & 32 & 46 & 68 & 28 & 59 & 46 & 37 & 48 & 42 \\
\hline Letonia & 0 & 0 & 22 & 12 & 48 & 31 & 98 & 98 & 79 & 0 & 28 & 25 & 26 & 25 \\
\hline Lituania & 0 & 0 & 8 & 9 & 104 & 57 & 91 & 95 & 89 & 93 & 27 & 25 & 27 & 26 \\
\hline Madagascar & 37 & 31 & 20 & 27 & 6 & 23 & 38 & 48 & 11 & 13 & 45 & 35 & 67 & 51 \\
\hline Malawi & 2 & 2 & 8 & 17 & 33 & 25 & 63 & 81 & 10 & 10 & 47 & 39 & 74 & 67 \\
\hline Malta & 24 & 39 & 10 & 12 & 17 & 14 & 100 & 100 & 100 & 100 & 23 & 24 & 12 & 14 \\
\hline México & 27 & 28 & 10 & 6 & 16 & 24 & 89 & 94 & 75 & 84 & 30 & 22 & 32 & 26 \\
\hline Moldavia & 16 & 13 & 8 & 21 & 19 & 19 & 93 & 96 & 79 & 85 & 32 & 28 & 30 & 29 \\
\hline Namibia & 1 & 1 & 15 & 5 & 36 & 77 & 79 & 90 & 28 & 32 & 37 & 34 & 47 & 50 \\
\hline Nepal & 49 & 59 & 23 & 59 & 25 & 28 & 77 & 86 & 21 & 34 & 56 & 45 & 65 & 52 \\
\hline Nicaragua & 5 & 12 & 44 & 31 & 30 & 38 & 80 & 85 & 48 & 52 & 28 & 21 & 32 & 18 \\
\hline Nigeria & 1 & 1 & 6 & 6 & 17 & 7 & 55 & 63 & 33 & 29 & 62 & 58 & 76 & 72 \\
\hline Noruega & 15 & 12 & 2 & 3 & 47 & 36 & 100 & 100 & 100 & 100 & 23 & 23 & 12 & 14 \\
\hline Países Bajos & 51 & 47 & 6 & 6 & 46 & 36 & 100 & 100 & 100 & 100 & 24 & 24 & 12 & 13 \\
\hline Pakistán & 84 & 98 & 15 & 17 & 19 & 23 & 88 & 91 & 37 & 47 & 47 & 50 & 56 & 60 \\
\hline Panamá & 7 & 6 & 38 & 93 & 82 & 41 & 90 & 94 & 67 & 72 & 35 & 28 & 33 & 32 \\
\hline Portugal & 47 & 47 & 12 & 14 & 58 & 22 & 98 & 100 & 98 & 100 & 26 & 26 & 13 & 13 \\
\hline Reino Unido & 4 & 2 & 7 & 9 & 58 & 18 & 100 & 100 & 100 & 100 & 20 & 22 & 10 & 12 \\
\hline Rep. Checa & 1 & 1 & 4 & 4 & 91 & 27 & 100 & 100 & 100 & 100 & 27 & 24 & 27 & 27 \\
\hline Rep. Corea & 52 & 52 & 3 & 3 & 44 & 8 & 93 & 98 & 100 & 100 & 25 & 25 & 10 & 14 \\
\hline
\end{tabular}


Tabla 9B (Continuación)

Indicadores de seguridad alimentaria utilizados (\%). (Cont)

\begin{tabular}{|c|c|c|c|c|c|c|c|c|c|c|c|c|c|c|}
\hline & \multicolumn{2}{|c|}{$\begin{array}{l}\% \text { Tierra de } \\
\text { cultivo } \\
\text { equipada con } \\
\text { sistemas de } \\
\text { riego* }\end{array}$} & \multicolumn{2}{|c|}{$\begin{array}{c}\% \\
\text { Importaciones } \\
\text { de alimentos } \\
\text { sobre } \\
\text { exportaciones } \\
\text { totales* }\end{array}$} & \multicolumn{2}{|c|}{$\begin{array}{l}\text { Variabilidad del } \\
\text { suministro de } \\
\text { alimentos per } \\
\text { cápita }\end{array}$} & \multicolumn{2}{|c|}{$\begin{array}{c}\text { \% Población con } \\
\text { acceso a fuentes } \\
\text { mejoradas de } \\
\text { agua }\end{array}$} & \multicolumn{2}{|c|}{$\begin{array}{c}\text { \% Población con } \\
\text { acceso a } \\
\text { instalaciones de } \\
\text { saneamiento }\end{array}$} & \multicolumn{2}{|c|}{$\begin{array}{l}\text { Frecuencia de } \\
\text { anemia entre } \\
\text { mujeres } \\
\text { embarazadas }\end{array}$} & \multicolumn{2}{|c|}{$\begin{array}{l}\text { Frecuencia de } \\
\text { anemia entre } \\
\text { niños de menos } \\
\text { de } 5 \text { años de } \\
\text { edad }\end{array}$} \\
\hline Unidades & \multicolumn{2}{|c|}{$\%$} & \multicolumn{2}{|c|}{$\%$} & \multicolumn{2}{|c|}{$\begin{array}{c}\text { Kilocalorías por } \\
\text { persona y día }\end{array}$} & \multicolumn{2}{|c|}{$\%$} & \multicolumn{2}{|c|}{$\%$} & \multicolumn{2}{|c|}{$\%$} & \multicolumn{2}{|c|}{$\%$} \\
\hline Países & 2000 & 2010 & 2000 & 2010 & 2000 & 2010 & 2000 & 2010 & 2000 & 2010 & 2000 & 2010 & 2000 & 2010 \\
\hline Rep. Dominic. & 32 & 38 & 45 & 17 & 66 & 36 & 86 & 82 & 77 & 81 & 39 & 32 & 33 & 33 \\
\hline Rumanía & 33 & 35 & 6 & 8 & 38 & 44 & 84 & 0 & 72 & 0 & 30 & 26 & 27 & 27 \\
\hline Rusia & 4 & 4 & 6 & 6 & 35 & 41 & 95 & 97 & 72 & 70 & 26 & 23 & 26 & 26 \\
\hline Sudáfrica & 11 & 13 & 3 & 4 & 15 & 33 & 87 & 94 & 65 & 73 & 33 & 30 & 33 & 40 \\
\hline Suecia & 5 & 6 & 3 & 5 & 26 & 18 & 100 & 100 & 100 & 100 & 23 & 24 & 12 & 13 \\
\hline Suiza & 9 & 15 & 3 & 3 & 12 & 15 & 100 & 100 & 100 & 100 & 25 & 25 & 12 & 13 \\
\hline Tailandia & 36 & 41 & 2 & 2 & 50 & 47 & 92 & 96 & 91 & 94 & 30 & 30 & 25 & 29 \\
\hline Túnez & 14 & 16 & 9 & 11 & 82 & 31 & 89 & 96 & 82 & 89 & 32 & 29 & 24 & 29 \\
\hline Turquía & 20 & 25 & 4 & 5 & 35 & 24 & 93 & 100 & 87 & 91 & 31 & 28 & 33 & 30 \\
\hline Ucrania & 7 & 7 & 4 & 6 & 37 & 76 & 97 & 98 & 95 & 94 & 28 & 25 & 27 & 26 \\
\hline Yemen & 33 & 56 & 21 & 30 & 20 & 17 & 60 & 55 & 39 & 53 & 41 & 37 & 61 & 60 \\
\hline
\end{tabular}

*Media móvil nivel 3.

Fuente: Elaboración propia según datos de FAO (2016). 
